\title{
Literature Review on Modeling of Density Difference Pumping Strategy for Geothermal Applications
}

Lucas A. Ware

West Virginia University, laware@mix.wvu.edu

Follow this and additional works at: https://researchrepository.wvu.edu/etd

Part of the Other Mechanical Engineering Commons

\section{Recommended Citation}

Ware, Lucas A., "Literature Review on Modeling of Density Difference Pumping Strategy for Geothermal Applications" (2020). Graduate Theses, Dissertations, and Problem Reports. 7983.

https://researchrepository.wvu.edu/etd/7983

This Problem/Project Report is protected by copyright and/or related rights. It has been brought to you by the The Research Repository @ WVU with permission from the rights-holder(s). You are free to use this Problem/Project Report in any way that is permitted by the copyright and related rights legislation that applies to your use. For other uses you must obtain permission from the rights-holder(s) directly, unless additional rights are indicated by a Creative Commons license in the record and/ or on the work itself. This Problem/Project Report has been accepted for inclusion in WVU Graduate Theses, Dissertations, and Problem Reports collection by an authorized administrator of The Research Repository @ WVU. For more information, please contact researchrepository@mail.wvu.edu. 
Literature Review on Modeling of Density Difference Pumping Strategy for Geothermal Applications

Lucas A. Ware

Follow this and additional works at: https://researchrepository.wvu.edu/etd

Part of the Other Mechanical Engineering Commons 


\title{
LITERATURE REVIEW ON MODELING OF DENSITY DIFFERENCE PUMPING STRATEGY FOR GEOTHERMAL APPLICATIONS
}

\author{
Lucas Ware
}

\author{
Problem Report submitted \\ to the Benjamin M. Statler College of \\ Engineering and Mineral Resources \\ at West Virginia University \\ in partial fulfillment of the requirements \\ for the degree of
}

Master of Science

in

Mechanical Engineering

Terence Musho, Ph.D., Chair

Nigel Clark, Ph.D.

Roy Nutter, Ph.D.

Department of Mechanical and Aerospace Engineering

Morgantown, West Virginia

2020

Keywords: geothermal, airlift, modeling

Copyright@2020 Lucas Ware 


\section{Abstract \\ LITERATURE REVIEW ON MODELING OF DENSITY DIFFERENCE PUMPING STRATEGY FOR GEOTHERMAL APPLICATIONS}

Lucas Ware

The utilization of geothermal ground heat sources has been demonstrated at both large and small scales across the world. However, methods of extraction of the hot working fluids are often a source of energy inefficiency and high capital expense. Current techniques to extract geothermal fluids rely on mechanically and electrically driven down-hole components that require maintenance on a regular basis. In providing a solution, one approach that reduces complexity, decreases maintenance, and allows access to fluids at greater depth is an airlift approach. The airlift approach relies on injection of gas at a depth within a geothermal well to lift the working fluid to the surface using a density difference pumping strategy.

This literature review focuses on existing methods and approaches to modeling the system throughout three scales: a microscale, intermediate scale, and macroscale. The microscale focuses on modeling considerations near the sparger head during bubble formation. The intermediate scale focuses on modeling techniques for characterizing bubble coalescing and gas hold-up. The macroscale focuses on modeling approaches over large length scales using a driftflux model. Because of the varying phenomena experienced within the well, specifically complex bubble behavior and gas hold-up, it was a consensus amongst the literature to require a combination of in-depth experimental testing in combination with simulations to properly capture airlift flow rates.

This literature review provides a review of modeling approaches that could be used to design a geothermal airlift system. Overall, the airlift system has the potential future application for power generation, district heating, and residential heating/cooling in geographic regions previously not considered based on existing technologies. The computational tools are currently available but it will require in-depth study of geothermal fluids under two-phase flow regimes.

Keywords: geothermal, airlift, modeling 


\section{Acknowledgements}

West Virginia University, what a ride it has been! I would never have completed my Master's degree without the support and assistance from many people who I do not have the space to individually thank. However, everyone in my life has played a part in this journey.

I would first like to thank all of my professors and colleagues at WVU. This specifically includes my research advisor, Dr. Terry Musho, who offered patience and guidance during a global pandemic and throughout my time as one of his graduate assistants.

Dr. Melissa Morris showed me how to be both professional and relatable in the workplace. Her dedication to her craft and caring for her students exemplified how an engineer should be. I will always treasure our office conversations and Chic-fil-A runs. Dr. Greg Thompson was always willing to talk about current and future classes, the outdoors, and life in general. He gave me some very helpful advice as I navigated through a difficult time, and I cannot thank him enough.

I would like to especially thank a life-long friend and WVU die-hard, Jim Foley, who hired me as a freshman at the university and put up with me for the next 4 years. His leadership and management skills gave me the knowledge and confidence to tackle anything in my college studies and I learned some of life's lessons from him that will stay with me forever.

I cannot leave WVU without expressing my gratefulness for the help and encouragement from my closest friend from engineering, Freddy Stalnaker. We survived on long nights of studying and McDonald's trips for most of our undergraduate career, and it was our teamwork that got me to where I am.

My deepest appreciation goes to all of my family members and particularly my parents, Mike and Melinda. Your unrelenting support of my educational goals helped push me to this point and I could not have done it without either of you. Thank you Mom and Dad. 


\section{Table of Contents}

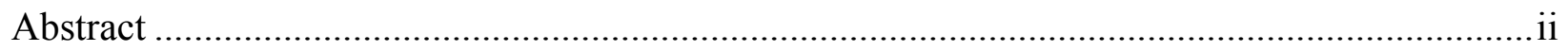

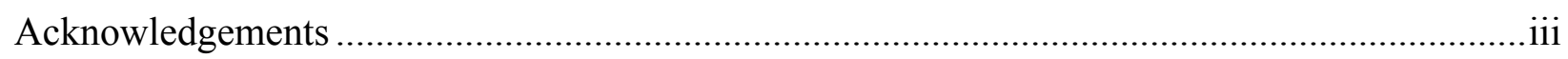

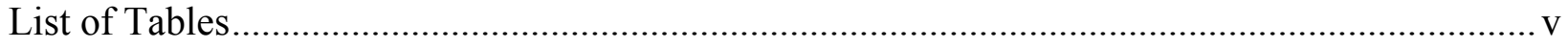

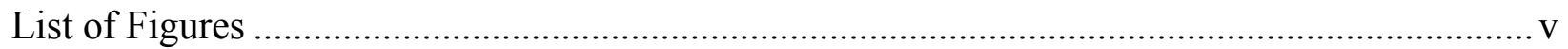

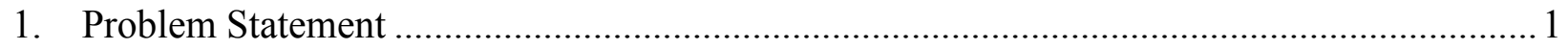

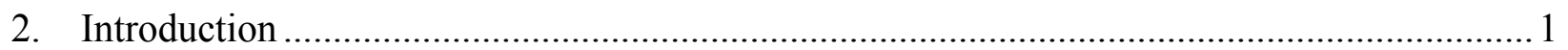

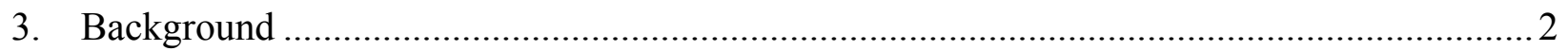

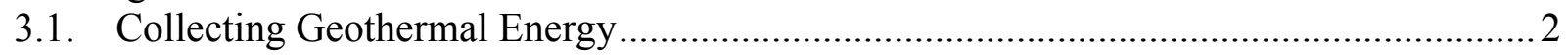

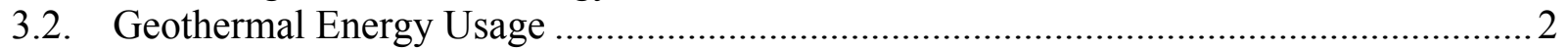

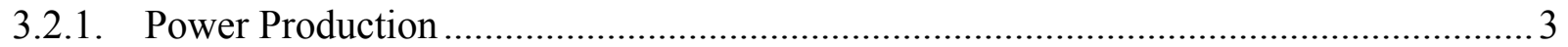

3.2.2. Residential and District Heating ……………....................................................... 5

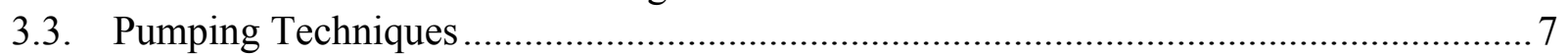

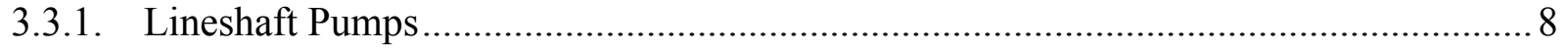

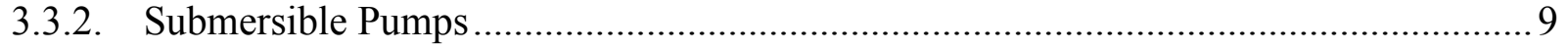

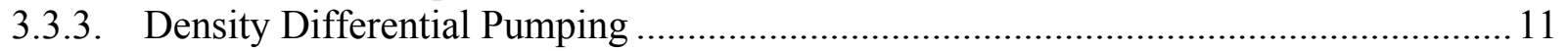

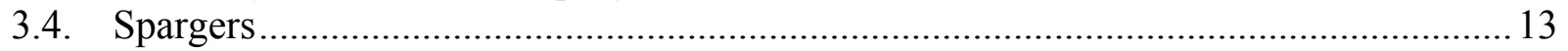

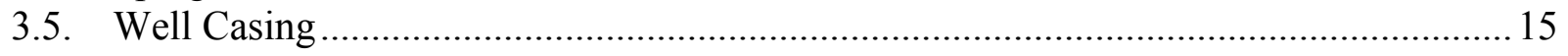

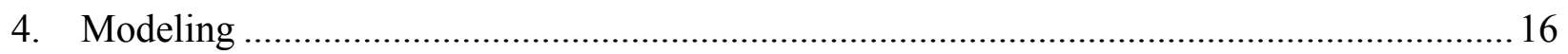

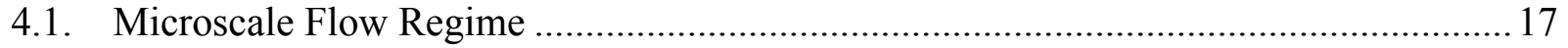

4.1.1. Microscale Modeling Approach............................................................................ 17

4.1.2. Microscale Consideration of Orifice Size Effect ......................................................... 19

4.1.3. Microscale Consideration of Gas Flow Rate Effect...................................................20

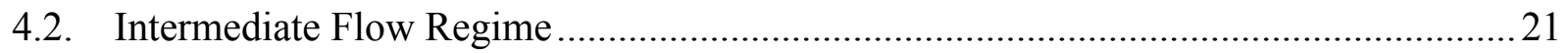

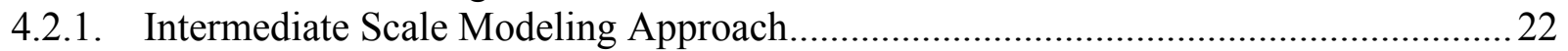

4.2.2. Intermediate Scale Consideration of Gas Hold-Up.................................................2.

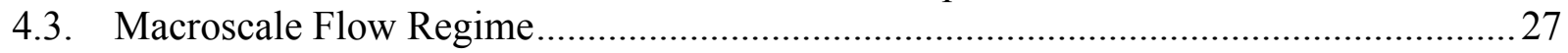

4.3.1. Macroscale Modeling Approach ...........................................................................2 29

4.3.2. Macroscale Consideration of Flow ……………….................................................. 30

4.3.3. Macroscale Consideration of Multi-point Air Injection................................................... 34

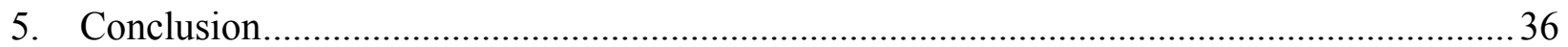

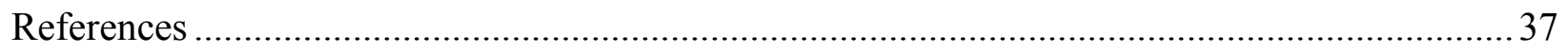




\section{List of Tables}

Table 1: This table presents the utilization of geothermal heat pumps in terajoules per year. ....... 7

\section{List of Figures}

Figure 1: Dry steam (a), flash steam (b), and binary (c) power plants are depicted.................... 4

Figure 2: All three power plants have differing regions of enthalpy under which they operate..... 5

Figure 3: More high-temperature availability is located in the western half of the United States.. 6

Figure 4: The lineshaft pump keeps the motor and pump head above ground.......................... 8

Figure 5: The electrical submersible pump can be used for deep geothermal wells.................... 9

Figure 6: The beam pump draws oil to the surface using a sucker rod..................................... 11

Figure 7: This is a basic layout for the geothermal well in a density differential approach........ 12

Figure 8: Sieve plates (A), radial (B), spider (C) and multi-ring spargers (D) are shown........... 14

Figure 9: The diagram shows the stepping of dimensions in a well casing.............................. 15

Figure 10: The regions are the microscale (1), intermediate scale (2), and macroscale (3)........ 16

Figure 11: These photos show a sparger with different pore diameters at equal gas flow rates...20

Figure 12: Three photos show a sparger with constant diameter at three increasing flow rates...21

Figure 13: The square bubble column shows the progression of the two-phase flow................24

Figure 14: The slope of the gas hold-up curve for two experiments are shown to be similar......25

Figure 15: Bubble, slug, churn, and annular flow is experienced in two-phase mixtures. ..........227

Figure 16: An airlift pump immersed in a well is shown with lift and submergence labelled. ....28

Figure 17: Bubble and bubble-slug flow are associated with early stages of the airlift process. . 30

Figure 18: Slug flow can look like either of these images................................................... 31

Figure 19: Churn flow (left) and annular flow (right) are where most inefficiencies occur.........32

Figure 20: The transition frame from slug flow to churn flow is shown in this diagram. ........... 33

Figure 21: Flow rates for air and water with several submergence ratios is shown. ..................34

Figure 22: Multi-point air injection is desired for an air flow flux above the critical point. ........ 35 


\section{Problem Statement}

Geothermal energy is a reliable and renewable energy source that currently accounts for $0.2 \%$ of the total U.S. energy consumption. New technologies to the field to reduce costs and increase efficiencies are extremely coveted. This literature review will explore the strategy behind using a density difference pumping strategy based on airlift principles with geothermal wells to harvest the vast amount of energy contained within the Earth. Background research into the current market will provide insight into current pumping methods and residential and commercial usage. Additionally, a three-scale analysis of modeling techniques will examine how a geothermal well might perform under the airlift principle.

\section{Introduction}

With the ever-changing fossil fuel industry and the uncertainties that arise from government regulations, there is a need to investigate as many alternative energy methods as possible. One of those alternative energy sources is the utilization of ground heat (geothermal) to produce electricity and for heating and cooling applications. Currently, geothermal energy is largely being applied to power production and district and residential heating/cooling. One of the critical requirements for utilizing these technologies is the method of bringing the working fluid (brine) to the surface in an efficient manner.

The overall efficiency of the process increases as the costs associated with the extraction methods decrease. This is even more important in geographical locations where the sub-surface ground temperatures are moderate, and the static level of the working fluid is deep. The following review focuses on a specific lift technology known as a density difference approach and the modeling techniques that might be utilized to incorporate this strategy in future geothermal applications. This approach creates a two-phase fluid mixture via a high-pressure, gas-introducing sparger at various depths of the geothermal well. This method will allow for more rapid harnessing of the geothermal energy than what is available and used in the commercial and residential markets today.

Collecting this thermal energy efficiently, as with any energy production system, is at a premium, and methods to improve the technological components can be crucial in the outlook for the geothermal industry. To make geothermal energy more appealing, investments into the 
industry should be made to reduce upfront and maintenance costs by developing new materials and methods of extraction. This report is interested in the utility of differential pumps for liquid extraction and, more specifically, which computational methods are necessary to optimize a differential density pump strategy.

\section{Background}

This literature review is concerned with a new technology being proposed for the capturing of geothermal energy. While all aspects of the process are equally important, it is also imperative to note that this is not a full design or analysis of the well, system, or individual components. Therefore, a complete understanding of some elements of this report may require an insight into the geothermal energy field.

\subsection{Collecting Geothermal Energy}

Prior to exploring the current production and usage of geothermal energy, it will be helpful to understand how this energy is harnessed. Geothermal brine, or a mixture of hot water and steam, is created through both natural and synthetic processes. Some thermal reservoirs contain pockets of pre-existing water that can be accessed by way of a production well through permeable rock below the Earth's surface ${ }^{1}$.

Other reservoirs are dry in nature and require a water injection system to create the brine, also known as an enhanced geothermal system. This high-pressure cold water is introduced to the underground areas through an injection well at depths ranging from one-half mile to three miles $^{1}$. The cold water forces itself through by fracturing, or expanding existing fractures, in the underground rock, which then absorbs the heat and becomes the working fluid. The new, hot fluid is then harvested through a production well as is the case with existing hydrothermal reservoirs.

\subsection{Geothermal Energy Usage}

According to Lawrence Livermore National Laboratory, the estimated U.S. Energy consumption for 2019 has geothermal energy contributing 0.21 out of 100.2 quads, or roughly $0.2 \%$ of the total energy consumption ${ }^{2}$. Of the 0.21 quads, or 210 trillion BTUs, 20 trillion BTUs 
are used commercially, 40 trillion BTUs residentially, and 140 trillion BTUs of this harvested geothermal energy is used to generate electricity. There are different reasons why geothermal energy is not as common among energy sources, but the most glaring is the high capital and maintenance costs compared with that of other energy sources. A residential geothermal heat pump installation will cost about twice as much as a traditional HVAC unit, but with tax incentives offered in most states and countries, the break-even period can be anywhere from 2-10 years $^{3}$.

Geothermal energy is considered a renewable source, meaning heat can be replenished to the well at the same rates it is extracted. Sustainability and renewability are different topics, however, with the former accounting for the economical, ecological and environmental profits and losses. For renewability, the sub-surface reservoir determines the overall heat capacity and prospect for maintaining a reliable source of energy. The first electricity-producing power plant using geothermal energy began in Lardarello, Italy in 1904 and is still active today. This is an example of the sustainability of the geothermal energy source ${ }^{4}$.

\subsubsection{Power Production}

Three primary types of geothermal power generating plants exist today: dry steam, flash steam, and binary power plants. These are all electricity producing plants that are powered by geothermal energy. Conversion efficiencies are calculated for the plants by the ratio of the generated electric power to the thermal heat harvested from the reservoir. The efficiencies of the power plants range from $1 \%$ in some binary plants to $21 \%$ in one of the highest-performing drysteam plants. For calculation purposes, $12 \%$ is the average efficiency that is used while most of the recorded power plants fall between $10-17 \%{ }^{5}$. Figure 1 shows all three of the main geothermal power plant configurations ${ }^{4}$. 


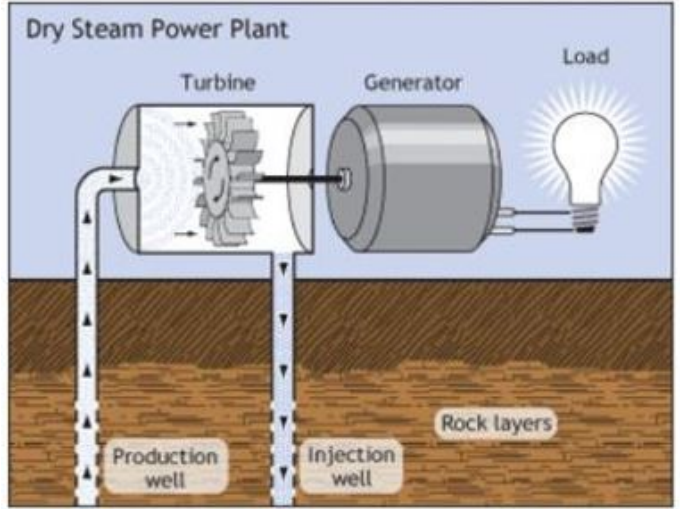

a) Dry Steam Power Plant

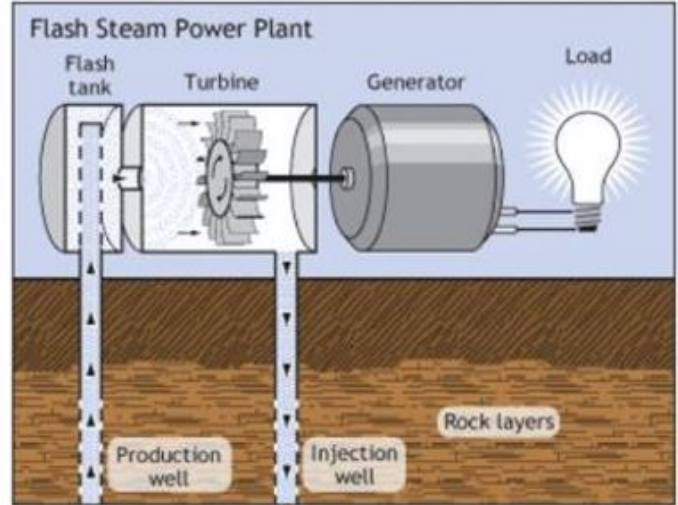

b) Flash Steam Power Plant

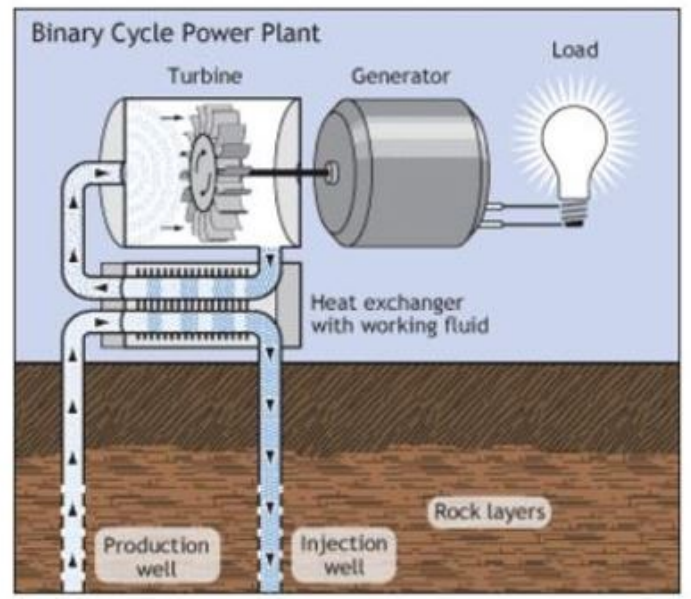

c) Binary Power Plant

Figure 1: Dry steam (a), flash steam (b), and binary (c) power plants are depicted ${ }^{4}$.

Figure 1a represents a dry steam power plant. This concept involves harnessing steam from the earth and directing it to a turbine driven generator. Due to the pressure and the momentum of the steam, the turbine spins at a high velocity, creating power. The average efficiency of a dry steam power plant is the highest among the three geothermal plants. The most efficient drysteam plant recorded in the Moon and Zarrouk study was the Darajat Unit 3 Power Plant located in West Java, Indonesia and it had an efficiency of $21 \%{ }^{5}$.

The second is a flash steam power plant, shown in Figure 1b. The difference between a flash and dry steam plant is there is a flash tank held at a lower pressure before the turbine, allowing the fluid to rapidly vaporize and enter the turbine at a higher energy. The fluid can also be "flashed" or processed through the tank a second time to harness even more energy. 
Figure 1c depicts a binary power plant, which uses a heat exchanger and a second fluid with a lower boiling point to drive the turbine and generators. These plants have proven to be the least efficient compared to dry and flash steam, but they are still used for their ability to operate at lower temperatures and without exposing the turbine to the corrosive fluids. Figure 2 portrays the regions of enthalpy in which each of these power plants will generate electricity ${ }^{5}$.

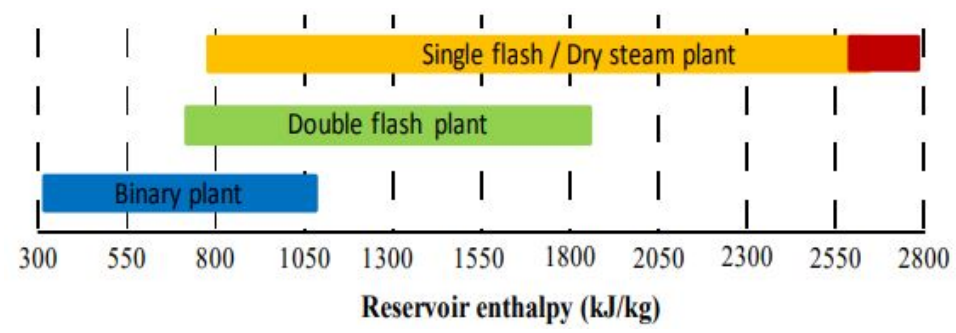

Figure 2: All three power plants have differing regions of enthalpy under which they operate ${ }^{5}$.

Reservoir enthalpies directly correlate to the efficiency of a power cycle, which leads to binary systems possessing the lowest efficiency among the three primary power plants. Pressure losses are also vital in efficiency calculations, which is why the proposed method of injecting gas into the well to decrease harvest time is believed to be key in maintaining the highest production rate at the best efficiency possible. Reducing thermal and pressure losses using the density differential pumping strategy will lead to both an efficiency increase for geothermal electricity generating power plants and higher usage among commercial and residential applications ${ }^{6}$.

\subsubsection{Residential and District Heating}

Direct use of geothermal energy for residential or district heating purposes has been utilized for centuries with ancient Roman, Chinese, and Native American cultures using the water for cooking, bathing, and heating ${ }^{7}$. Today, geothermal energy can be used to heat individual or clusters of buildings. It can also be used for practical industries, such as food dehydration and milk pasteurization. The western United States has the most plentiful resources of geothermal energy within the country, which leads to cities in states such as Nevada and Idaho having an established network of underground piping to heat buildings, melt snow and supply 
greenhouses $^{8}$. Figure 3 shows a map of the average sub-surface temperatures across the United States that reveals the geothermal energy resources within the country ${ }^{9}$.

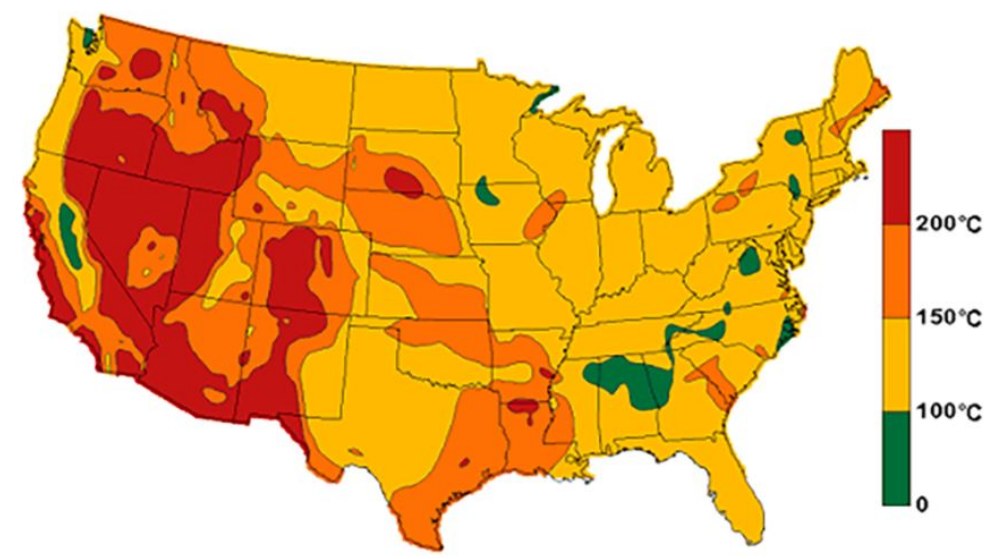

Figure 3: More high-temperature availability is located in the western half of the United States ${ }^{9}$.

The western and midwestern parts of the country possess the higher subsurface temperatures but there is a capability to harness forms of geothermal energy throughout the U.S.

Compared to the overall geothermal market in the United States, district heating is a small contributor. It consisted of 800 billion BTUs of the roughly 200 trillion BTUs $(0.4 \%)$ of geothermal energy used in $2014^{8}$. Even with these amounts there are benefits in using district heating, which include having cleaner local air, reducing the usage and transportation of fossil fuels, and ultimately a lower cost of energy.

Reykjavik, Iceland began district heating for its citizens in 1930. Today, over half of the people living in the city uses geothermal water for water heating ${ }^{10}$. Geothermal pricing for house heating in Iceland ranges from 1.5-3.5 US-cents/kWh. While comparing that price with the 7 US-cents/kWh national average price for oil heating, it is easy to see why Iceland, a country with several low and high temperature fields, utilizes as much geothermal energy as they can.

Geothermal heat pumps account for over half (59.2\%) of the worldwide annual geothermal energy usage ${ }^{11}$. From 2015 to 2020, the reported worldwide number of installed 12kWequivalent heat pump units increased by 54\%. That 54\% increase represents the jump in available capacity from only heat pumps. Other categories of utilization include greenhouses, agriculture, industrial processes, and bathing/swimming. Table 1 shows the average annual 
energy usage in terajoules/year (TJ/year) from these and other categories across five-year increments from 1995 to $2020^{11}$.

Table 1: This table presents the utilization of geothermal heat pumps in terajoules per year ${ }^{11}$.

\begin{tabular}{|l|r|r|r|r|r|r|}
\hline \multirow{2}{*}{ Utilization } & \multicolumn{5}{|c|}{ Utilization TJ/year } \\
\cline { 2 - 7 } & $\mathbf{2 0 2 0}$ & $\mathbf{2 0 1 5}$ & $\mathbf{2 0 1 0}$ & $\mathbf{2 0 0 5}$ & $\mathbf{2 0 0 0}$ & $\mathbf{1 9 9 5}$ \\
\hline Geothermal heat pumps & 599,981 & 326,848 & 200,149 & 87,503 & 23,275 & 14,617 \\
\hline Space heating & 162,979 & 88,668 & 63,025 & 55,256 & 42,926 & 38,230 \\
\hline Greenhouse heating & 35,826 & 29,038 & 23,264 & 20,661 & 17,864 & 15,742 \\
\hline Aquacultural pond heating & 13,573 & 11,953 & 11,521 & 10,976 & 11,733 & 13,493 \\
\hline Agricultural drying & 3,529 & 2,030 & 1,635 & 2,013 & 1,038 & 1,124 \\
\hline Industrial uses & 16,390 & 10,454 & 11,745 & 10,868 & 10,220 & 10,120 \\
\hline Bathing and swimming & 184,070 & 119,611 & 109,410 & 83,018 & 79,546 & 15,742 \\
\hline Cooling/snow melting & 2,589 & 2,596 & 2,126 & 2,032 & 1,063 & 1,124 \\
\hline Other & 1,950 & 1,440 & 955 & 1,045 & 3,034 & 2,249 \\
\hline Total & $\mathbf{1 , 0 2 0 , 8 8 7}$ & $\mathbf{5 9 2 , 6 3 8}$ & $\mathbf{4 2 3 , 8 3 0}$ & $\mathbf{2 7 3 , 3 7 2}$ & $\mathbf{1 9 0 , 6 9 9}$ & $\mathbf{1 1 2 , 4 4 1}$ \\
\hline \% increase in 5 years & $\mathbf{7 2 . 3}$ & 39.8 & 55.0 & 43.4 & 69.6 & \\
\hline
\end{tabular}

The total utilization of these residential and district heating categories has increased over $800 \%$ since 1995 and will continue to grow as long as there is available geothermal energy within the Earth (essentially forever for our purposes barring a catastrophic event or circumstances).

\subsection{Pumping Techniques}

There are varying methods used in extracting geothermal liquid, or brine, from underground thermal reservoirs. Most of these methods include the use of pumps, with the two most common being line shaft pumps and submersible pumps ${ }^{12}$. The main problem occurring with the use of these pump systems is failure as a result of harsh conditions experienced by the components inside the well.

The density differential pump strategy will apply innovative technology to extract the brine, removing these costly and high-maintenance pumps from the wells. All moving and serviceable components for this new design will be located above ground, lowering upfront and maintenance costs, as well as downtime ${ }^{6}$. 
Many advantages and disadvantages are present with existing geothermal pumps. This section looks at the pros and cons of these pumps and how the new method proposed here will aim to eliminate some, if not all, of their problems.

\subsubsection{Lineshaft Pumps}

Lineshaft pumps (LSPs) contain a centrifugal pump, motor at the surface, and an extended driveshaft that rotates within a lubrication column ${ }^{12}$. Flow can be regulated and the majority of parts in these systems can be maintained from the surface with intent of running at peak efficiency more often. LSPs run at lower speeds than a submersible pump (discussed in the next section), which yields less wear, and longer life, of the motor and other parts. Figure 4 depicts a lineshaft pump and its primary components ${ }^{13}$.

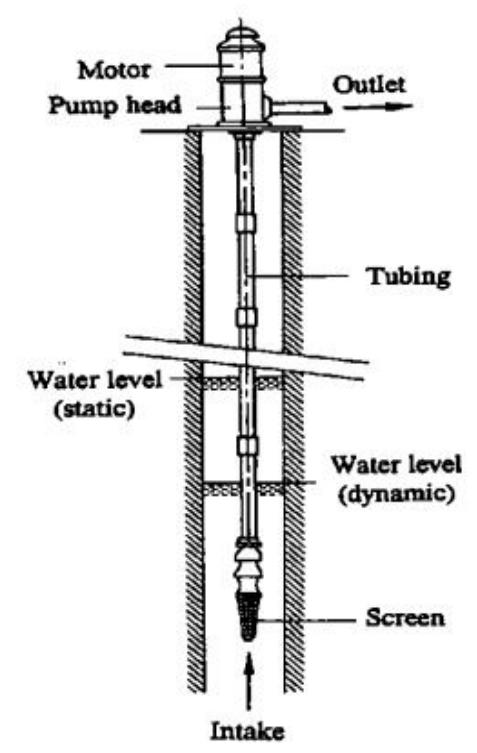

Figure 4: The lineshaft pump keeps the motor and pump head above ground ${ }^{13}$.

A lineshaft, or vertical, pump for geothermal use is generally used at mid to high-range temperatures, namely 150 to $200{ }^{\circ} \mathrm{C}$. These pumps are currently the most commonly used in geothermal wells ${ }^{12}$. This popularity stems from the absence of electrical parts within the well, and the relative ease of maintenance. Eliminating as many components from the hostile underground environment as possible is paramount in increasing times between necessary maintenance and in lowering the overall costs for the energy. 
Even though LSPs are the most commonly used geothermal pump, there are still concerns with the naturally corrosive conditions they are exposed to. Frequent maintenance and downtime are often experienced. A geothermal power plant in Soultz, France equipped with a lineshaft pump was removed or reinstalled seven times between its installation in 2008 and a publication presenting its results in $2015^{14}$. These were due to various operational and technical failures related to abrasion and corrosion. 4 of these 7 halts in production were attributed directly to erosion of moving parts, with the other 3 coming in the form of a leaking part and an electrical failure. There was only one maintenance service scheduled during that time period.

\subsubsection{Submersible Pumps}

Electrical submersible pumps (ESPs) are similar in concept to lineshaft pumps, with the main difference coming in the form of the motor being located within the well at some depth. A cable stretches from the motor to the electricity supply at the surface. An ESP is required when the well depth reaches more than $250 \mathrm{~m}^{12}$. One common disadvantage for ESPs is they normally only work with low enthalpy values of water and temperatures up to $120{ }^{\circ} \mathrm{C}^{15}$. Figure 5 shows a schematic of a standard ESP and its critical components ${ }^{13}$.

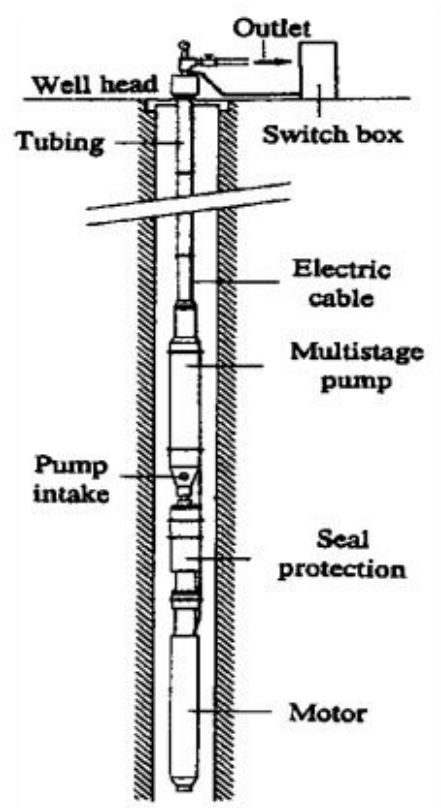

Figure 5: The electrical submersible pump can be used for deep geothermal wells ${ }^{13}$. 
One main concern for the life of submersible pumps is the initial installation plus the sizing and rating of the equipment. Proper design parameters such as fluid properties, productivity, flow rate, and other data must be considered when installing these pumps ${ }^{15}$. Additional parameters such as the geothermal environment and the everyday operations have an impact on the life of an ESP. These factors can ultimately lead to decreased running times and efficiency if not designed properly. Proper housing material and coatings can prevent corrosion of the motor within the well, but certain safeguards and precautions are still necessary to protect against the chemically altered water and the suspended abrasive solids ${ }^{13}$. These solids typically consist of sand or small rock particles, and high liquid velocities with these solids can cause abrasion and erosion within the pumping equipment.

Failures that occur in ESPs are generally electrical. Mechanical issues, however, usually cause this failure. Vibrations within the machinery naturally occur and can wear down the critical parts over extended periods of time. They are the suspected causes of many types of failures in high-speed mechanical systems. Manufacturing defects also play a role in premature failure of submersible pump systems ${ }^{15}$.

In the petroleum industry, a beam pump uses reciprocating vertical motion of a sucker rod inside a well casing to withdraw oil liquids to the surface. The mechanical movement of a motor, crank, belt-pulley, beam, "horse head" and sucker rod system shown in figure 6 pulls the oil from a well $1^{16}$. 


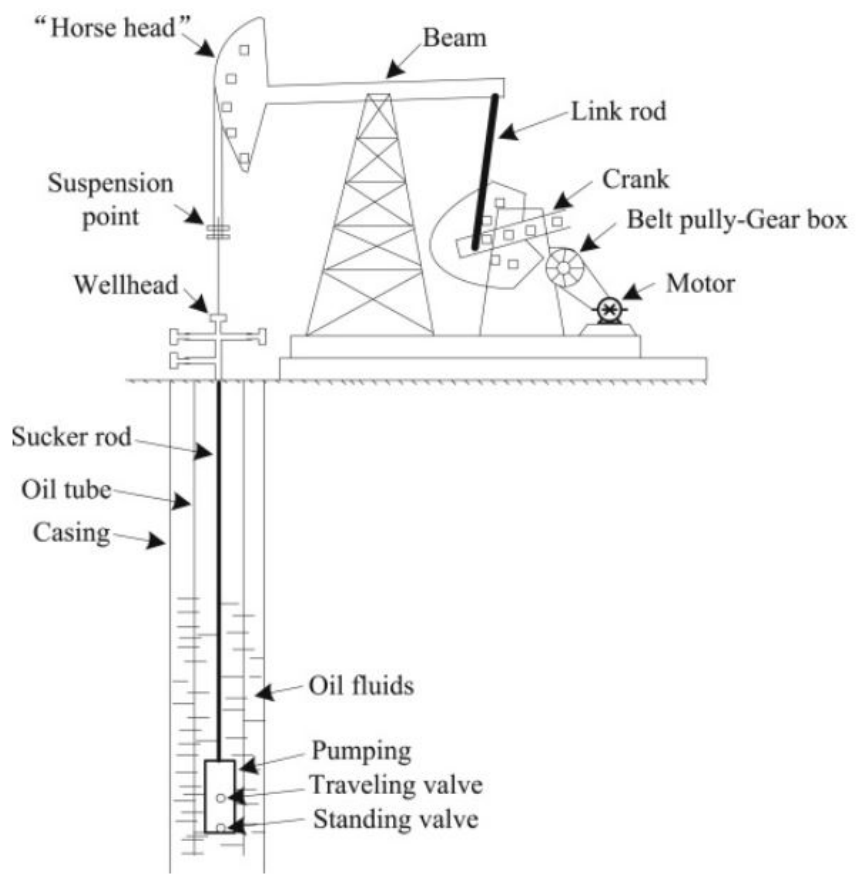

Figure 6: The beam pump draws oil to the surface using a sucker rod ${ }^{16}$.

Most of its parts are above ground but this system still requires maintenance due to fatigue and harsh working conditions. A model developed by Miska on beam,or sucker rod, pumping systems shows that simulation discrepancies appear when the inertia of the fluid is neglected ${ }^{17}$.

\subsubsection{Density Differential Pumping}

The density differential pumping technique shown in figure 7 was developed based on airlift principles to create a two-phase mixture of water and air above an injection point that will rise to the surface and be available for use in power-generation plants or residential/direct use ${ }^{6}$. A sparger with numerous pores, which can be thought of as an air-injecting showerhead, will introduce bubbles in the geothermal well to develop the mixture and assist in the recovery process. Multipoint air injection along the depth of the well with optimized sparger designs will contribute to peak bubble flow and formation. The differences in buoyancy of the mixture and well water will allow for hot and pressurized fluid to be pumped to the surface.

The complexity of the fluid flow requires analysis of bubble formation across several length scales, as well as the flow type throughout the scale range. The fourth section of this report 
investigates the flow and bubble formation across these scales in more detail, with attention to the two-phase mixture and how the fluid properties and dynamics affect the overall system.

Some of the following innovations within this design will greatly reduce the overall costs for the proposed system. A simulation using the characteristics of each well will permit the control system for this design to customize required airflow and other specifications, determine the expected water flow rate, and project additional important inputs and outputs such as expected downtime and pumping power. This will cut down on the time it takes to optimize the pump to each well. Recapturing some of the air pressure at the surface will allow for less pumping input power and increased overall efficiency. The absence of exposed electrical components in the well will grant longer periods of time between maintenance and a longer overall life expectancy of the system and individual components.

This report does not address the full design of a geothermal well, but instead will explore the multi-scale modeling techniques for the governing and understanding of the fluid flow and mixtures. Figure 7 shows the fundamental components of the density differential strategy. The well bore and casing will use standards for geothermal wells that will govern the model effectively. These standards include but are not limited to the bore diameter, well casing thickness, and materials.

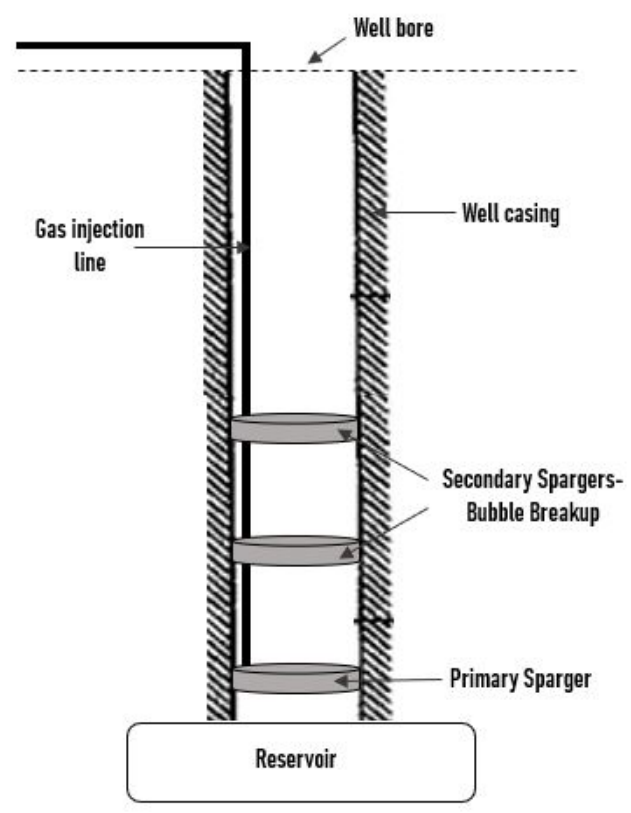

Figure 7: This is a basic layout for the geothermal well in a density differential approach. 
Some of the parts within this new design, aside from the mainstay components of a geothermal system, will require background information and an analysis. One of these parts is a sparger. Well casings and injection lines supplying the pressurized gas to the sparger will need to be able to withstand the high temperatures and pressures and corrosive environment associated with geothermal wells. The new density difference concept depends on the gas injection creating the right mixture of bubbles to bring the pressurized brine to the surface. The sparger(s) will play the most important role in that process.

\subsection{Spargers}

A sparger is a device used to inject a gas into a liquid. It can be thought of as a showerhead plate, but rather than injecting water into air it injects air into water, or brine. They are used daily for fish tanks and soda carbonation, but there are additional applications which make them appealing for an assortment of applications. Chemists use spargers to control processes such as oxidation, fermentation, and hydrogenation ${ }^{18}$. With concern to the density difference strategy, implementation of a sparger can reduce the total amount of piping needed to inject the gas into the well, and it can eliminate the need for a mixer altogether. These two advantages will contribute to the reduction of upfront costs of tapping into a geothermal reservoir. In a well, a limited amount of space is set aside for piping, wiring, and other down-hole components. Decreasing the volume of piping will allow for a smaller well diameter to be used for drilling, which in turn leads to less required work and smaller expenses in the initial construction phases.

Metal designs of spargers, or gas distributors, can be used where there are corrosive conditions, e.g., geothermal wells. An ideal sparger for the density difference approach will introduce small bubbles evenly over the entire, or part of the, cross-section of the well. There are optimal orifice qualities such as size, number, and distribution pattern that can be used for varying bubble size, air flow rate and pressure, and the pressure of the sparger's environment. These designs can be a variety of shapes and sizes, which include a sieve plate (Figure 8A), radial sparger (Fig. 8B), spider sparger (Fig. 8C), and multi-ring sparger (Fig. 8D), among others $^{20}$. The selection of sparger design will govern the bubble formation sizes and gas hold-up profile, along with flow pattern and mass and heat transfer rates ${ }^{19}$. Finite element analysis (FEA) of the well and the expected flow environment will aid in the sparger design selection process. 


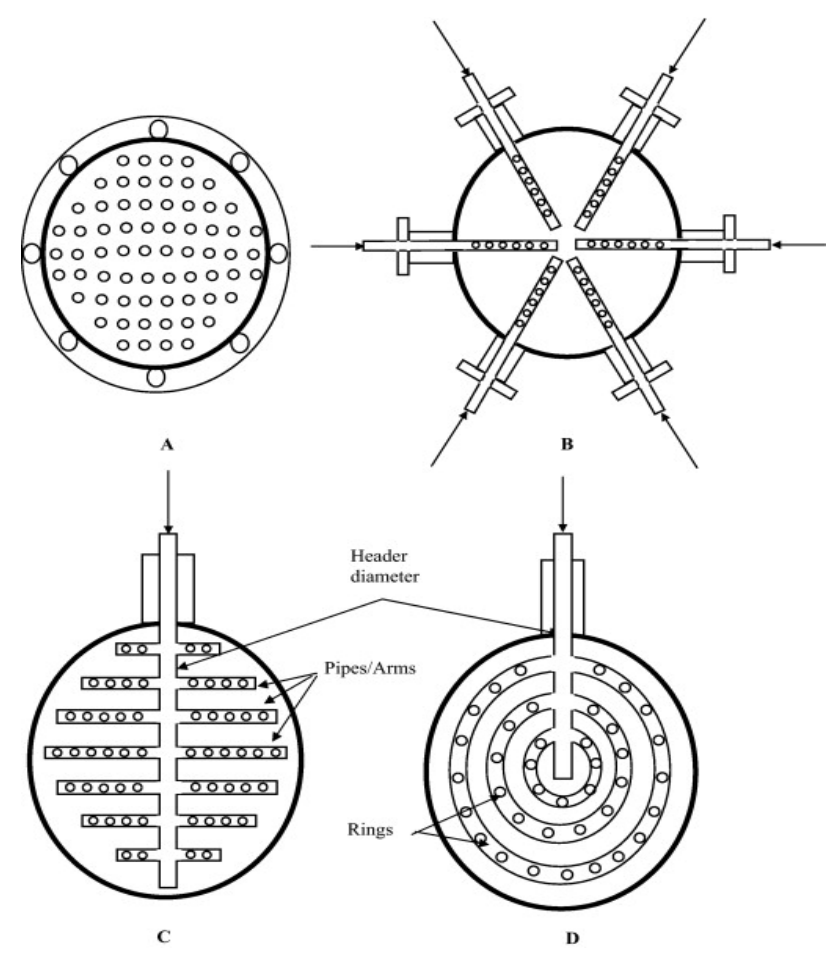

Figure 8: Sieve plates (A), radial (B), spider (C) and multi-ring spargers (D) are shown ${ }^{20}$.

Certain critical design problems may arise if an improper sparger selection occurs. One of the main problems is known as weeping, or the uneven residential time distribution and higher pressure drops in the well ${ }^{20}$. All pressure losses will accumulate over the full system, so it is important to try and reduce the possibility of these losses when possible. Non-uniform distribution of orifice sizes can also cause dead zones, which is another increased region of pressure drops. Spider and multi-ring spargers are shown to provide high non-uniformities among bubbles ${ }^{20}$. Acting under the assumption that the geothermal well performs best under uniform conditions, the best selection of sparger design would be a standard single-ring or radial.

SGS is a company that produces spargers for the mining and oil and gas industries. Their high pressure sparger is made from stainless steel and has a sustainable differential pressure of $1200[\mathrm{kPa}]$ and maximum air flow rate of $200\left[\mathrm{~m}^{3} / \mathrm{hr}\right]^{21}$. A prediction of pressure and temperature profiles carried out by Barelli, Carsana, Lombardi, and Maran for Geothermics estimated that a well with a depth of $1340 \mathrm{~m}$ would possess a hydrostatic pressure of $7850 \mathrm{kPa}$, or roughly 6 times that of the sustainable operating pressure of an SGS stainless steel sparger ${ }^{22}$. 


\subsection{Well Casing}

Geothermal well construction is complicated and not part of this literature evaluation. It is, however, important to know the general specifications and standards that are used for future simulations. High temperature geothermal wells can range from a few hundred to 4,000 meters, with petroleum wells going up to $10,000 \mathrm{~m}$. Inner diameters for the deepest casing in a well supplying a power station are commonly $95 / 8$ ", with the casing at the well bore being closer to 20 ,23. Figure 9 shows an example of a geothermal well drilled to $2,000 \mathrm{~m}$.

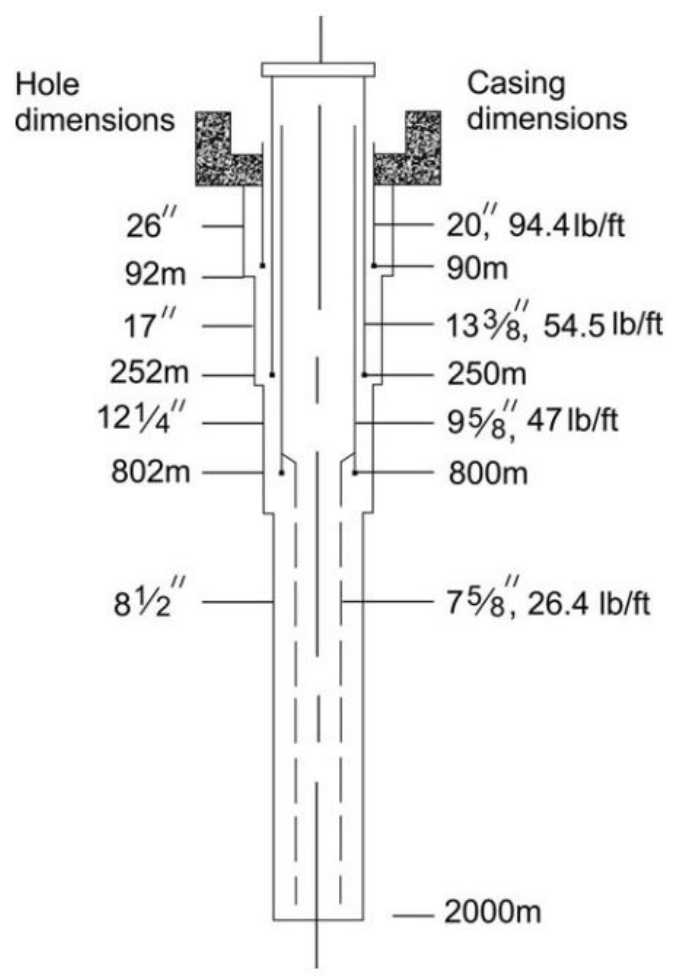

Figure 9: The diagram shows the stepping of dimensions in a well casing ${ }^{23}$.

The left side shows the size of the outer drilling bore while the right side labels the diameter of the steel casing at various depths. Stability and longevity are the influential reasons for the size stepping at $90 \mathrm{~m}, 250 \mathrm{~m}$ and $800 \mathrm{~m}$. 


\section{Modeling}

Multi-scale modeling of the density differential approach and the principles behind the airlift technology is required to gain a full understanding of the bubble characteristics, as different regions of the geothermal well will experience varying behaviors of flow. A three-scale approach to fully analyze the lift process will be required due to the length over which the bubbles traverse. A large portion of the modeling literature reviewed in this report is from experiments using bubble columns and pipes and the findings from their technical papers.

Figure 10 is not to scale but illustrates the three regions that will be instrumental in the process. The first region, which is closest to the primary sparger head, will require a microscale modeling approach. The second region is an intermediate analysis, followed by a third and macroscale approach. The macroscale analysis will include the investigation of slug flow and how it interrupts the behaviors of a two-phase mixture.

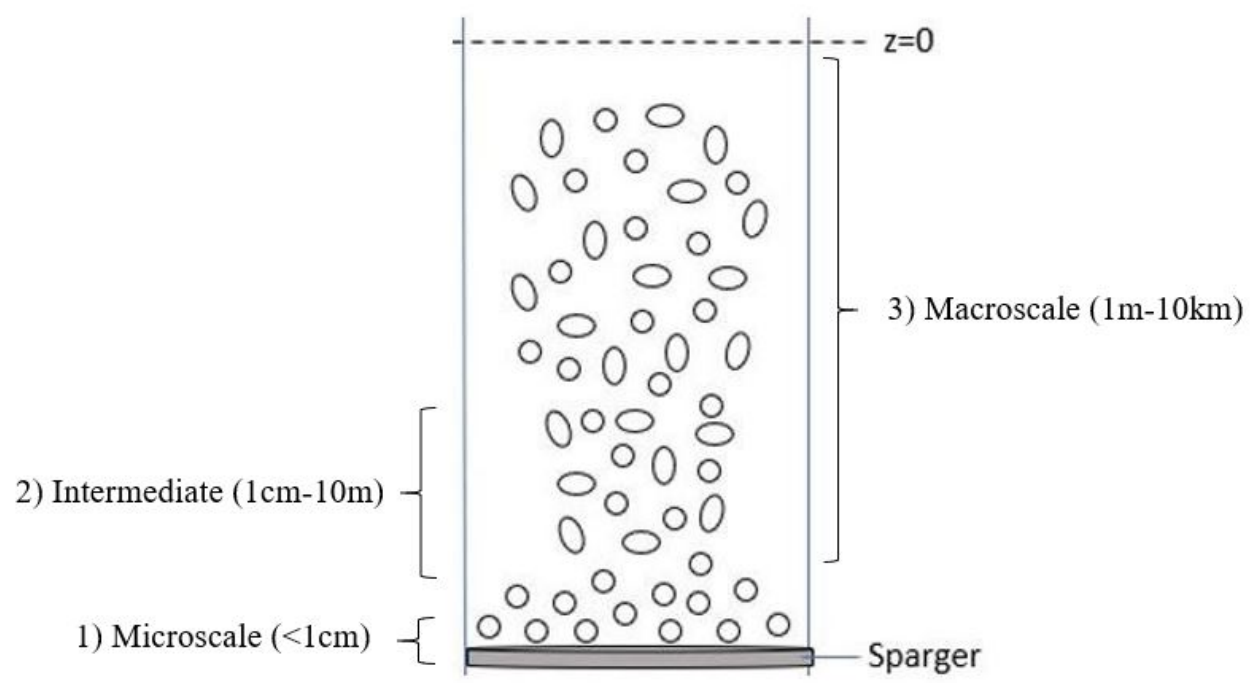

Figure 10: The regions are the microscale (1), intermediate scale (2), and macroscale (3).

At a microscopic level, the sparger will produce bubbles at the orifices that will begin to coalesce above the sparger head and combine with neighboring bubbles, all the while interacting with the walls. This is the stage where technology has the most control over the process. Orifice size, gas flow rate, and fluid properties will determine how efficient the pump is at delivering geothermal brine to the surface ${ }^{24}$. 
The intermediate scale will review literature that employed computational fluid dynamics (CFD) models that best represent the proceedings of the expected bubble flow. This includes the investigation of the behavior of an air bubble at hydrostatic pressures, during wall interactions, and the interactions with surrounding water.

The macroscale will look to understand how the entire process could operate over the entire length of the well. The macroscopic review will combine what occurs at the microscopic and intermediate levels and the rest of the way to the free surface to predict the overall dynamics of the flow regime from the sparger to the free surface.

\subsection{Microscale Flow Regime}

A microscopic simulation of the flow is useful when trying to determine the effects of twophase mixtures on bubble flow. The Navier-Stokes (NS) equation requires assumptions when dealing with the creation and infancy flow of bubbles, since there is a continuously changing makeup of the fluids. Therefore, approximations are made in a finite volume approach to solve the NS equations. The flow to be experienced in this system is erratic and there are many variables and phenomena that need to be considered. These factors include but are certainly not limited to the behaviors of bubbles in a liquid and the behaviors of bubbles amongst themselves. However, this is not enough to disregard the need for the Navier-Stokes equations and the role they can play in predicting the microscale regime. It will demand a combination of numerical analyses and a conclusion on which one(s) will best fit the data.

In general, the microscale can look at how different variables affect the formation of bubbles at high hydrostatic loads and the interaction with the orifice geometry. Neighboring gas bubbles can affect each other just by their presence. Different sparger designs can make all the difference when attempting to reduce the effect of a surrounding liquid on bubbles. Orifice sizes and gas flow rates are two of the most important factors when creating bubbles within a column or in this case, a well. The following section elaborates into how these components attribute to the overall development of this phase.

\subsubsection{Microscale Modeling Approach}

An equation that is commonly used to govern flow in the transition regime of an experimental bubble column is the Boltzmann equation of kinetic theory. When coupled with the 
Bhatnagar-Gross-Krook (BGK) approximation, the Boltzmann equation can be derived into a lattice method that can still use the rigorous results of the Boltzmann equation that have already been completed ${ }^{24}$.

A lattice-Boltzmann method (LBM) uses kinetic energy equations to investigate multiphase flow using finite discretization and the collision propagation method ${ }^{25}$. A two- or threedimensional approach can be taken, and a flow field with trajectories can be computed based on Newton's law of motion. LBM has long been used with isothermal and incompressible fluid flows. This approach is employed due to the uncertainty of behaviors between fluids with a heat transfer rate that cannot be ignored at the molecular level. This uncertainty has led to many experiments "bottoming out," or stopped the progression of simulations that are used in modeling flow that is fully compressible and non-isothermal. Regularization, or simplification, can be used to reduce certain effects of high-order discrete components of the lattice-Boltzmann approach such as hydrodynamic forces and static and dynamic moments of the fluid ${ }^{25}$.

The behavior of bubbles between themselves can be analyzed using stochastic, or random, collision models. The collisions are simplified to being elastic and frictionless. The speed of a bubble post-collision can be projected by considering its previous velocity and the velocity of what it is colliding with ${ }^{25}$. Surface tension will also have control over this projected velocity. One method by Khalloufi applied surface tension force with a Dirac function as a volume source term in the Navier-Stokes equations ${ }^{26}$. The normal force to the mean curvature of the bubble was computed using a level set function. The authors also used a free slip boundary condition on the walls for an adaptive meshing simulation and no bubble breakup occurred.

The Boltzmann equation can be used to govern general fluid behavior and as a tool for CFD. Kurtoglu and Lin studied bubble dynamics and employed a lattice-Boltzmann method for single rising bubble simulations. Good agreement of bubble rise properties and variables, such as drag coefficient and wake characteristics, was found across all flow regimes between the current and previous experimental and numerical analyses ${ }^{27}$. An LBM can also be applied to droplet collisions and the full bubble flow regime. The coalescence of bubbles within a flow deform the bubbles more and more with time and create complicated shapes that are difficult to predict. Despite this difficulty in predicting the shapes, the flow field can still be generated for large density ratios between the two phases of fluid ${ }^{28}$. 
In the simulations carried out by Sungkorn, et al., they looked at the result of a collision of a bubble with an impeller in a mixing tank. The new linear velocity of the bubble was determined using the angular velocity of the impeller blade ${ }^{29}$. For the proposed density differential system, the velocity of the second particle can be determined by using the flow rate of the gaseous fluid coming out of the sparger. The Euler-Euler approach explored in their paper treats the twophases as interpenetrating continua. Phase interaction terms that appear in the conservation equations govern and describe the behavior experienced by the fluids ${ }^{30}$. This modeling method can also be used in correlation with the local bubble size distribution by solving population balance equations.

The Euler-Lagrange approach using a singular bubble and/or a pocket of smaller bubbles is described by Newton's law of motion and accounts for the interphase forces between the two phases. This approach is long, tedious, and rare in literature even with its ability to incorporate microscopic phenomena such as bubble-bubble interactions, bubble-wall interactions, and coalescence and breakup of bubbles. Bubble-bubble interactions are difficult to predict with the Euler-Lagrange method due to the high computational load ${ }^{31}$.

\subsubsection{Microscale Consideration of Orifice Size Effect}

An experiment carried out in a bubble column which detailed the effects on bubble formation caused by different factors concluded that pore size distribution, gas flow rate, and the liquid properties are most influential to the bubble development ${ }^{32}$. Drag, inertia, and surface tension resist the formation of bubbles while buoyancy, momentum, and gas pressure all aid the process. Monitoring which factors affect the different stages of the process is difficult and takes ample experimentation.

Monodispersed and uniform bubble size is a common assumption made when studying bubble column hydrodynamics using $\mathrm{CFD}^{32}$. However, initial size distribution at the sparger head is an important detail when developing a model that can accurately predict the activity of the bubble column. It was found in the study of liquid properties that a high viscosity activates more sparger pores and results in bubbles that are smaller in size and larger in number. Also noted is that many pores contribute to the formation of one bubble. Using a sparger with a small

number and uniform distribution of pores and a liquid with a low viscosity (water) would yield bubbles that are generally larger in size and ones that can be controlled a little easier. 
Conversely, a sparger with a larger number of smaller diameter pores will lead to more and smaller bubbles, which can be anticipated and predicted ${ }^{32}$. This is the desired effect for the proposed density differential pumping strategy to prevent slug flow behavior, which results in more inefficiency. Figure 11 shows a comparison between the sparger heads with two separate pore diameters, $40 \mu \mathrm{m}$ and $100 \mu \mathrm{m}^{32}$.

(a)
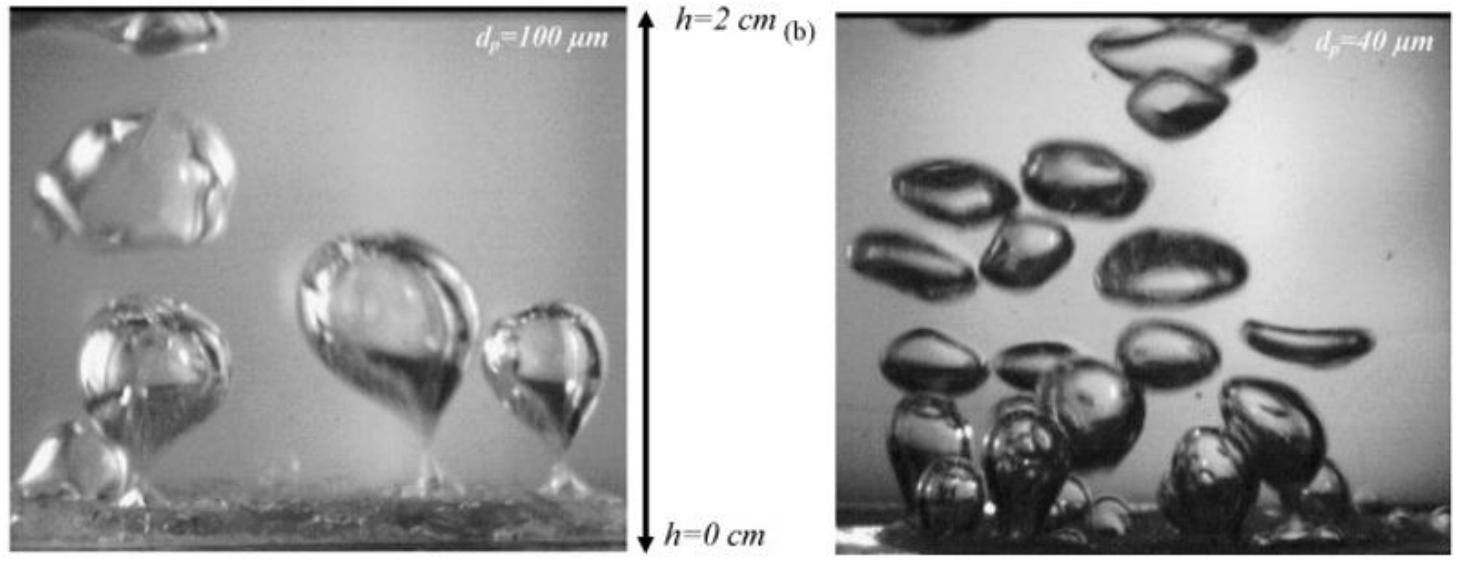

Figure 11: These photos show a sparger with different pore diameters at equal gas flow rates ${ }^{32}$.

Less and larger bubbles are shown in the figure to be generated when there is a larger diameter pore of $100 \mu \mathrm{m}$. Slug flow behavior is expected to happen more frequently when there are larger bubbles from the beginning.

\subsubsection{Microscale Consideration of Gas Flow Rate Effect}

While pore diameter of the sparger is an integral component of microscopic bubble formation, gas flow rate is also essential in creating the optimal bubble size and velocity. Figure 12 shows the results from three different flow rates exiting the same sparger pore diameter ${ }^{32}$. 
(a)

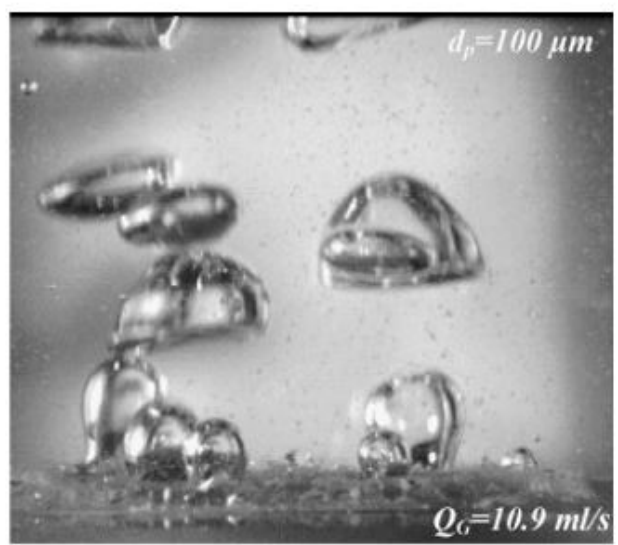

(b)

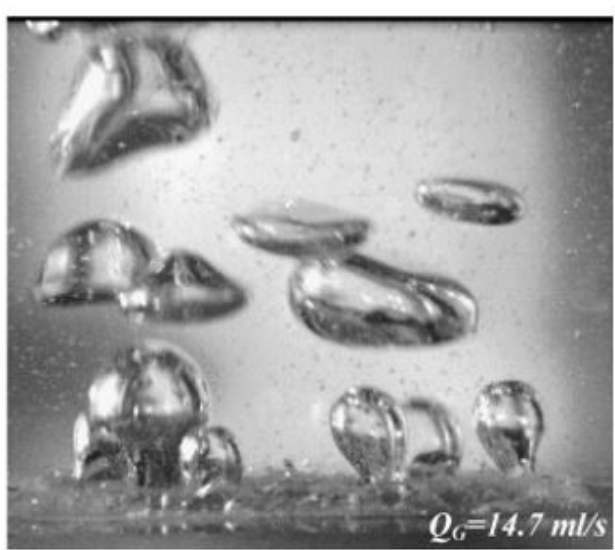

(c)

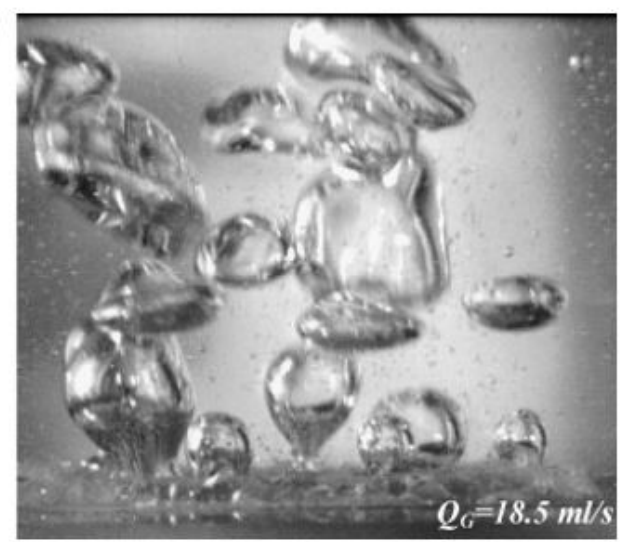

Figure 12: Three photos show a sparger with constant diameter at three increasing flow rates ${ }^{32}$.

When using the same sparger head and pore diameters, it is observed that higher gas flow rates lead to more and larger bubbles. The capillary pressure amongst the fluids can be overcome in smaller pores by using a high enough gas flow rate. These smaller pores, however, will then create smaller bubbles amongst the larger ones, thus establishing a mixing of bubble sizes. This phenomenon can lead to increased slug flow and the coalescence of bubbles, which ultimately restricts the vertical flow of the bubbles. To reduce the probability of this occurring, an ideal gas flow rate that creates similarly sized bubbles will need to be obtained ${ }^{32}$.

\subsection{Intermediate Flow Regime}

The overall effectiveness of the density differential pumping approach will rely on the ability of the bubbles to bring the geothermal brine laced fluid to the surface. In section 4.1, it was shown how the creation of the bubbles affected the liquid around the sparger and deep within the 
well. The intermediate scale will look to see how computational fluid dynamics and modeling software can be used to create profiles of the two-phase flow. Gas hold-up is an important behavior that occurs in vertical pipes and wells. Literature involving this unique behavior is also explored in this portion of the model.

\subsubsection{Intermediate Scale Modeling Approach}

Computational fluid dynamics rely on mass, momentum, and energy conservation laws and the resulting Navier-Stokes equations, which are difficult to solve analytically, to try to predict or describe the behavior of fluids ${ }^{33}$. In a CFD model, every fluid property is defined at each point in the domain. This domain can include varying size increments for specific techniques and approaches that are essential in how the fluid flow is analyzed and calculated. The governing differential equations and boundary conditions are also defined and generally solved by the modeling software ${ }^{34}$.

Physical laws including the momentum and energy balances of the multi-phase fluids is an ongoing investigation with governing equations still being developed and debated. Phenomenon such as bubble breakup and coalescence, along with drag and interfacial dynamics, lack the experimental proof that single-phase flow has shown ${ }^{35}$. It is difficult to introduce the assumed fluid properties and characteristics into a laboratory or isolated model. Nonlinearities in the analysis and mathematics such as convection, turbulence, and chemical reaction present difficulties in obtaining accurate solutions for complex fluid flows. A "guess value" strategy is employed to reduce the influence of these nonlinearities. Iterations are performed until the guess value of a nonlinear term and its computed solution are within an acceptable tolerance ${ }^{34}$.

Gas velocity and volume fraction variables can be simulated using ANSYS FLUENT or equivalent software programs ${ }^{35}$. FLUENT uses a finite volume approach for solving the governing equations, whereas COMSOL Multiphysics simulation software uses a finite element analysis. Ghorai and Nigam used an Euler-Euler model with FLUENT to simulate the two-phase

flow and variables ${ }^{35}$. Euler approaches use control volumes with flow fields of fluid properties to model the mixture. Momentum transfer is critical in this model in determining the empirical correlations for pressure drop and gas hold-up. Conservation of mass and momentum were ensured through iterations and numerical solutions were obtained for the initial and boundary 
conditions. Uniform profiles at the inlet and non-slip boundary conditions at the wall were imposed for the numerical analysis of turbulent flow ${ }^{35}$.

A CFD experiment carried out by Mubarok, et al., used FLUENT to validate pressure drop data from live geothermal fields ${ }^{36}$. The frictional and momentum pressure drops accounted for a large percentage in net pressure drop and these losses were numerically validated with the pressure gauge data from various geothermal wells. This model aimed to predict fluid pressure and velocity profiles that can be used to calculate the liquid mass flow rate at the outlet. The pressure losses and fluid mass flow rates were compared with geothermal well data and showed a relative error of less than $9 \%{ }^{36}$.

Software modeling can assist in the computation of the differential equations across the geometrical profile. The reactions of the bubbles in the geothermal well operating under the proposed strategy can be studied by using multiple stages of CFD to simulate different moments of time in the process. Bubble columns are one way to simulate what will occur inside of the well after introducing a gas into a liquid at a certain depth. CFD models of bubble columns can be characterized into two parts. A homogeneous flow structure with near-uniform bubble sizes that transition to a heterogeneous regime that contains a broad range of bubble diameters ${ }^{37}$.

Turbulence modeling will be necessary for this pumping approach, primarily on the intermediate scale. Large eddy simulations (LES) were introduced in the 1960s to simulate air flow in the atmosphere and more research (and computing power) since then has made it one of the most popular simulation techniques for turbulent flow ${ }^{38}$. One of the integral reasons why LES is successful in simulating the flow is because it ignores small length scales and focuses on the flow as a whole. It is assumed a better fit than other approaches, such as the Reynolds Averaged Navier-Stokes (RANS) ${ }^{39}$.

RANS methods can be used to model turbulent two-phase flow and can be coupled with averaged Euler-Euler approaches in applications involving multiphase $\mathrm{CFD}^{40}$. Averaging techniques to eliminate smaller scale issues are used to treat the two phases of flow as interpenetrating and the interfacial structure as one phase, even if liquid and gas states are present. The RANS approach is generally applied under isotropic assumptions at a large scale. However, most turbulent flows are unsteady and the anisotropic properties are present at the intermediate scale ${ }^{41}$. Support of the RANS modeling methods will eventually come in the form of LES and direct numerical simulations ${ }^{40}$. 
A direct numerical simulation (DNS) can be performed to solve the governing equations and gather data required to analyze two-phase flow. Force and coefficient values are obtained from these simulations and can be used in Euler-Lagrange models, among others ${ }^{42}$. Bubble size distributions can result from a DNS and provide more information on the bubble population. Volume of fluid (VoF) methods can also be performed using a DNS.

A numerical study by Jain, et al., used color functions within the VoF method to determine the amount of liquid present in the flow at a certain coordinate and time ${ }^{42}$. This approach also indicates the interface position and orientation by using the gradient of the color function. A harmonic average of the fluids was used to compute the overall fluid phase density and viscosity. In their study, bubble coalescence was determined by the resulting collisions between the bubbles. Bubble break-up was found to occur when the surface force of the bubble is less than the inertial forces acting on the outside. Figure 13 is three representations depicting the bubble regime and how the two-phase interface changes over time in a square column ${ }^{42}$.
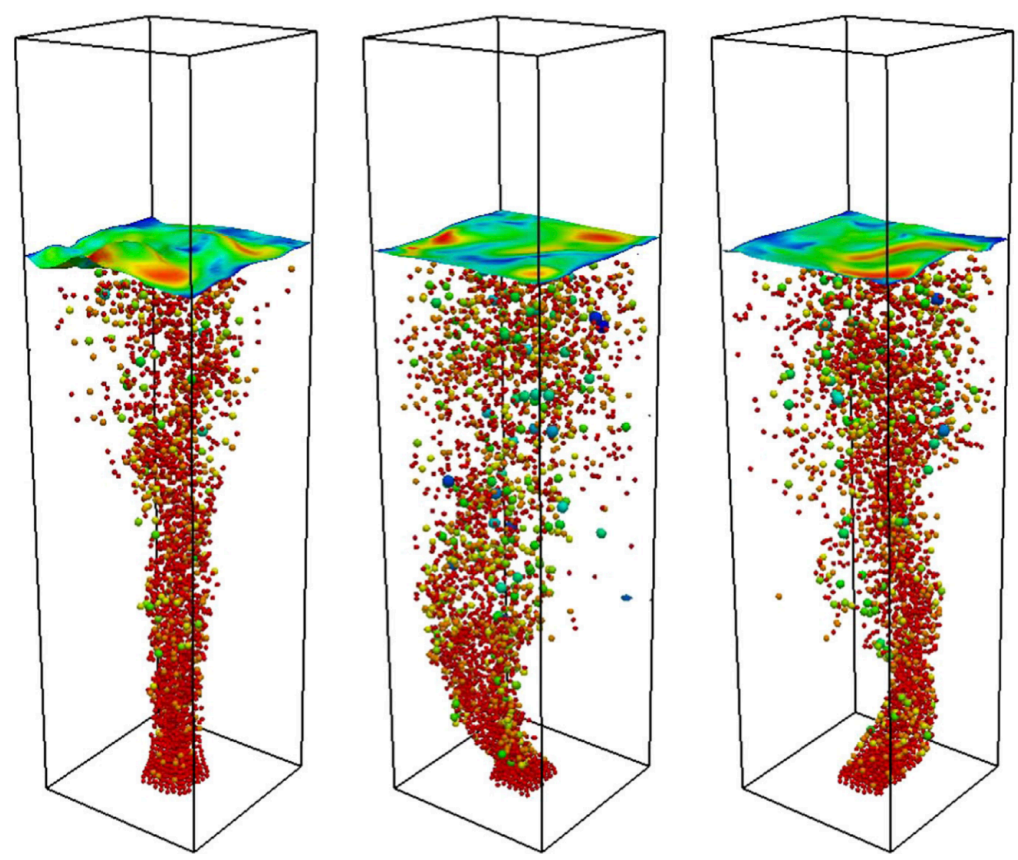

Figure 13: The square bubble column shows the progression of the two-phase flow ${ }^{42}$.

Using different gas velocity and fluid parameters can refine the results of their study. These parameters include the fluid properties and the initial bubble size at the gas distributor. 


\subsubsection{Intermediate Scale Consideration of Gas Hold-Up}

A phenomenon known as "gas hold-up" plays a key role in the heat and mass transfer rates between the gas and liquid. Gas hold-up can be defined as the fraction of the column's crosssectional area occupied by gas $\left(\mathrm{H}_{\mathrm{G}}=\mathrm{A}_{\mathrm{G}} / \mathrm{A}\right)$. An optimal ratio for a geothermal well can be found through iterations. Figure 14 shows the results from two experiments testing the gas holdup of a bubble column after introducing a gas via a sparger ${ }^{37}$.

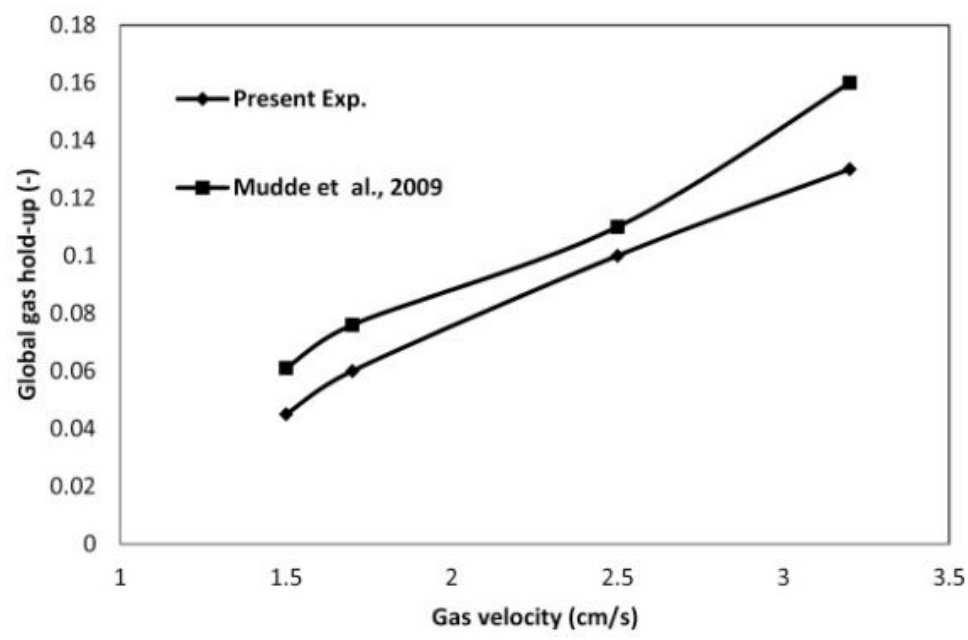

Figure 14: The slope of the gas hold-up curve for two experiments are shown to be similar ${ }^{37}$.

It is shown that the gas hold-up of a bubble column has a linear relationship with the gas velocity that is being introduced at the sparger. This is an important feature of the homogenous flow regime for bubbles ${ }^{37}$.

Radial gas hold-up results in the liquid rising near the center of the column and flowing downwards by the wall, while the gas bubbles rise to the surface after becoming large enough or they can recirculate with the liquid when smaller in size. The recirculation of smaller bubbles is due to the lack of momentum to escape the liquid flow loops. When the gas bubbles are just right in size, bits of liquid can become pressed in their streams and travel to the surface to be captured. Aside from gas hold-up, mixing within the bubble column occurs from bubble coalescence and breakup, turbulence, and the movement between the two fluids at any point caused by pressure differential and mass balance ${ }^{37}$. 
Surface tension and viscous forces will govern the flow regimes from the sparger to the ground, specifically in the intermediate scale where the bubbles are beginning to coalesce and interact with each other while moving at a high velocity. Fuster and Popinet carried out a simulation using a VoF method to review the effect of surface tension and viscosity ${ }^{43}$. They chose this approach for the advantage of volume conservation and the ability to obtain the evolution of the interface between the air bubble and liquid surfaces. Artificial transport of mass, momentum and energy is also avoided by using the VoF method. The authors realized the jump of properties across the interfacial area contribute to the difficulty in accounting for surface tension ${ }^{43}$.

According to an experimental study completed in a $2.8 \mathrm{~m}$ high bubble column by Moshtari, Babakhani, and Moghaddas, the superficial gas velocity at injection at the sparger plays the largest role in the amount of gas hold-up ${ }^{44}$. The bubble size distribution is another concern that influences the bubble hydrodynamics. Sparger size and design will play the largest role in initial bubble shapes and sizes. The homogenous flow regime turns to heterogeneous at higher gas flows. Major coalescence of slugs and the presence of annular flow are also experienced at higher gas flow rates ${ }^{44}$. This suggests there is a critical point of gas injection flow rate that could be obtained through numerical analysis and CFD.

CFD is helpful for simulating the flow of a two-phase mixture of gas and liquid. Accurate fluid properties are required in these simulations in order to apply the governing equations. Studies to measure bubble characteristics in vertical columns, wells, and reactors generally use data from fluids at atmospheric conditions to predict behaviors ${ }^{45}$. These studies, while helpful in experimental research, will not accurately portray the flow of a geothermal well. High pressures occur within the well and these increased pressures lead to increased bubble breakup, average bubble size reduction, and narrower size distributions. The transition between flow regimes will be delayed from these higher pressures, as well ${ }^{45}$.

Gas hold-up increases with multi-component liquids. The foaming that occurs due to the liquid will inhibit coalescence and reduce the size of the bubbles ${ }^{46}$. Contaminants in the mixture fall to the bottom of the bubble, which reduces its overall rise velocity capability ${ }^{47}$. The experiment by Parisien, et al., was performed to study a hydroprocessor experiencing high gas hold-ups that operates around pressures of $11.7 \mathrm{MPa}$ and temperatures of $440^{\circ} \mathrm{C}$. Simulations using a monofibre optical probe investigated the associated operating conditions and local bubble 
properties in the hydroprocessor ${ }^{45}$. This experiment calculated global gas hold-ups using a measured axial dynamic pressure profile. The structure of these hold-ups was examined by the dynamic gas disengagement technique proposed by Sriram and Mann by shutting off the gas flow to the column and tracking the regime throughout the disengagement ${ }^{48}$.

The probe used in the study by Parisien, et al., had difficulty detecting all bubbles because of the reduced size, increased pressure, and random axial rise of each bubble ${ }^{45}$. When a bubble was fully detected, its properties and characteristics was accurately measured and recorded. Bubble breakup and coalescence was restricted by the elevated pressures experienced in the column and the behaviors of the flow regimes. Gas velocity was impacted by the bubble size generated by the sparger. Energy dissipation was also present due to the sparger, which indicates the importance of the design of an efficient air distribution device ${ }^{45}$.

\subsection{Macroscale Flow Regime}

An airlift pump uses injected gas to create a two-phase fluid mixture to lift it to the top of the well or pipe. The lower density of the mixture allows buoyancy forces to help lift it through the liquid and rise upward. The four main flow regimes are sketched in Figure 15 and can be classified as bubble, slug, churn, and annular flows ${ }^{49}$.
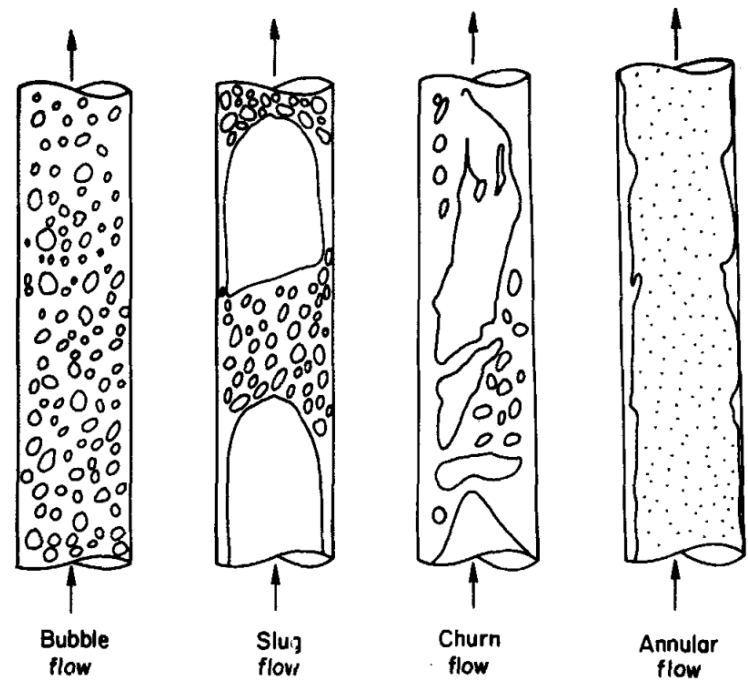

Figure 15: Bubble, slug, churn, and annular flow is experienced in two-phase mixtures ${ }^{49}$. 
For the design of airlift pumps, slug and annular flow are undesired due to their increased pressure losses and decreased pumping efficiencies associated with the air moving along the core of the pipe as opposed to the walls during these regimes. These intermittent flow patterns introduce instability and randomness in the pressure drop and heat and mass transfer ${ }^{50}$. Reducing slug and annular flow can decrease these instabilities and improve the overall flow regime.

Figure 16 shows an airlift tube immersed in a well ${ }^{52}$. The lift, $\mathrm{x}_{1}-\mathrm{x}_{2}$, is the amount of lift required to bring the mixture to the surface to be captured. This ratio of submergence, $x-x_{1}$, to total pump height, $\mathrm{x}-\mathrm{x}_{2}$, was found to dominate the airlift process and the one variable that most directly governs the lift ${ }^{52}$. The submergence ratio is equivalent to the volume of air required to lift a volume of water.

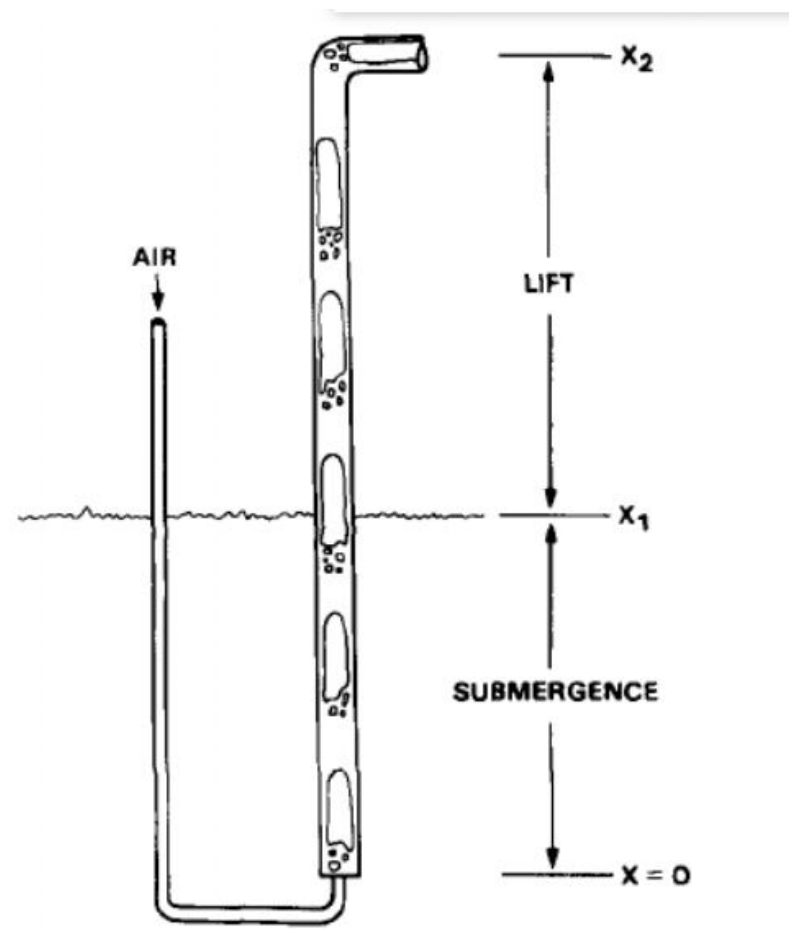

Figure 16: An airlift pump immersed in a well is shown with lift and submergence labelled ${ }^{52}$.

Drift-flux models have been used to predict losses associated with bubble slippage and slug flow. A design equation to predict the lift requirement of an airlift pump has also been derived from these models to simplify loss calculations and input requirements ${ }^{52}$. Experiments analyzing 
the different flow regimes and the effects of multi-point air injection have also been carried out and the results are discussed and shown in the sections below.

\subsubsection{Macroscale Modeling Approach}

A drift flux model was presented by Zuber and Findlay and is widely accepted to predict gas and liquid hold-up in two-phase mixtures of flow ${ }^{51}$. Clark and Flemmer used this model to predict bubble slip velocity and total flux. Slug presence through the flow increases local bubble slip and can explain some of the variation of the constant, $\mathrm{C}$, which accounts for velocity and gas void distributions. Gas void is not the same as the volumetric gas flow because of the ability for irregularities to develop across the pipe diameter. Other reasons for the variation in the constant include large bubble populations near the wall and an increase of gas voidage ${ }^{51}$. It can be assumed then, that an increase of well pipe diameter will cause the flow to be less symmetrical and predictable due to the complex behavior of bubbles in a vertical airlift column.

Clark and Dabolt came up with an explicit formula derived from theory to calculate lift in an airlift pump operating with a two-phase mixture ${ }^{52}$. They approximated the pressure loss due to wall friction and used a drift-flux model to form a general design equation for airlift pumps experiencing slug flow. Equation 1 shows the resulting equation used to calculate lift.

Equation 1: This equation is a derived formula to calculate lift using a drift-flux model ${ }^{52}$.

$$
\left(\frac{D n M-\varrho_{1} g M}{\left(\varrho_{1} g+D\right)^{2} S}\right) \log \left(\frac{R+\left(\varrho_{1} g+D\right) S P_{2}}{R+\left(\varrho_{1} g+D\right) S P_{0}}\right)+x_{2}=0
$$

Full derivation of the equation and explanation of the terms and process can be found in Clark and Dabolt's paper ${ }^{52}$. The curves generated from the new equation agree with curves generated through operational results of a range of air flow rates. This new equation is shown through experiment to apply to a range of operating conditions and pump heights ${ }^{52}$.

Gas- and liquid-hold-up were evaluated using a drift-flux model. These hold-ups account for energy losses due to bubble slippage and frictional losses which can be accounted for by using a single-phase flow equation, which has been modified to account for the other fluid ${ }^{52}$. The new design equation was generated through a trial and error basis by adjusting the liquid flow rate for 
a specific gas flow rate until the predicted lift matches the actual lift. This technique of trial and error is still used to accurately predict equations and in this case creates a better fit than deriving it from momentum and energy balances. Earlier methods required an iterative process along with an incremental analysis across the length of the well or tube.

\subsubsection{Macroscale Consideration of Flow}

The study and analysis of the four primary two-phase flow regimes is most important on the macroscale level. Figures 17, 18, and 19 show the different flow patterns encountered in an airlift pump $^{53}$.

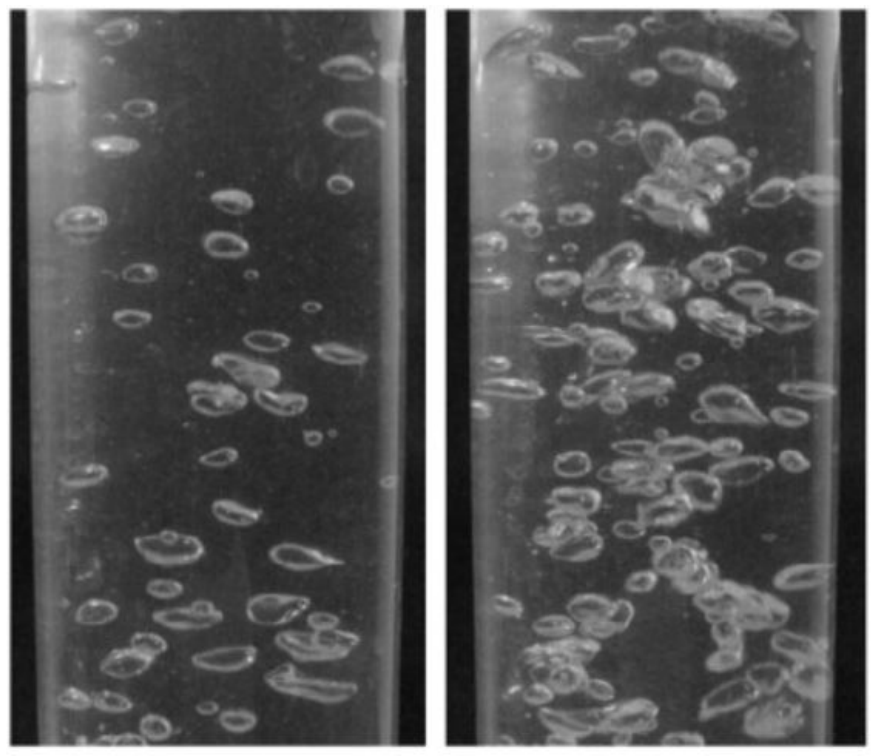

Figure 17: Bubble and bubble-slug flow are associated with early stages of the airlift process ${ }^{53}$.

Bubble flow on the left of Figure 17 is experienced in the initial phase where the air is introduced. The bubbles can be approximated as symmetrical and spherical with flat ends. Gravitational, inertial, and buoyancy forces dominate the two-phase mixture and the ability for the bubbles to flow uninterrupted ${ }^{53}$. Inertia forces from the injected air and natural buoyancy forces assist in the lift process of the mixture while gravity opposes them. The total of the first two forces need to be large enough to lift the gas-liquid mix to the free surface.

The pressure of the injection point is less than the surrounding pressure, which causes the water to move vertically up the well pipe. This is the main timeframe where bubble flow is 
present. This area of the well is also associated with a high submergence ratio, which as stated before is a dominating variable that governs the lift requirements ${ }^{53}$. Low flow rates of gas injection lead to standard bubble flow. As the injected flow rate increases, transitions from bubble flow to slug flow are experienced.

Air slugs, present in the slug flow regime shown in Figure 18, force the water trapped between them along the pipe wall. Pressure differences caused by the fast-moving air slugs drag water and smaller bubbles behind the large pocket of air.

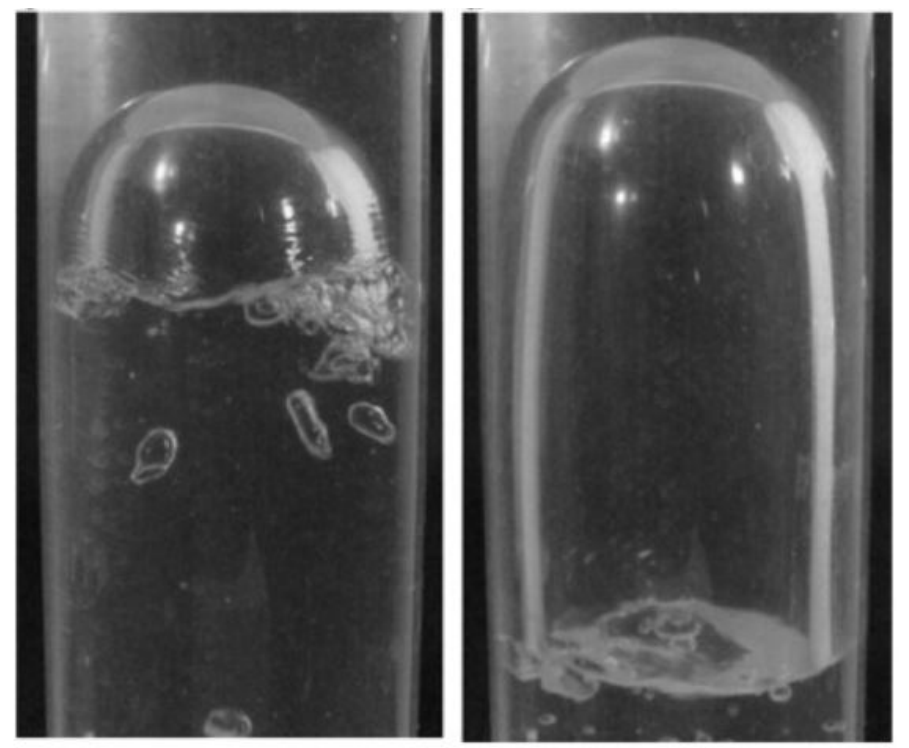

Figure 18: Slug flow can look like either of these images ${ }^{53}$. 
The increase of void fraction in the slug flow regime heavily increases the intricacy of the computational approaches ${ }^{54}$. The turbulent environment affiliated with this region will also increase the complexity of the interfacial structure.

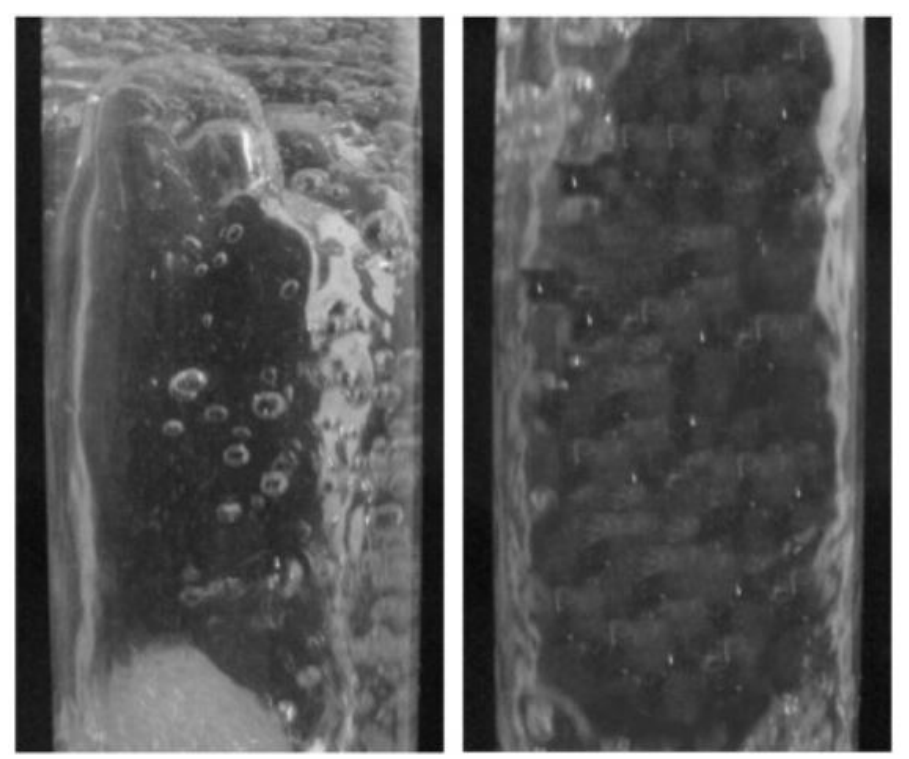

Figure 19: Churn flow (left) and annular flow (right) are where most inefficiencies occur ${ }^{53}$.

Churn flow, displayed on the left in Figure 19, is the transitional phase between slug and annular flow. It is irregular in nature due to the breaking down of large slugs and creation of the liquid film ${ }^{53}$. Vermeer and Krishna found in 1981 that no interactions occur between the small and large bubbles of churn flow ${ }^{55}$. However, Chen et al. concluded that the small bubbles remain near the wall during this flow region while the larger ones tend to stay in the center of the pipe ${ }^{56}$. Beyer et al. and Lucas et al. completed experiments that showed a combination of Vermeer and Chen's conclusions ${ }^{57,58}$.

Annular flow shown on the right in Figure 19 is the region where the airlift pump operates with the lowest efficiency. High air flow rates can cause the breaking up of the film in the annular region into small bubbles, while low flow rates will not allow for the vertical upflow of the regime. High velocity air and water interactions throughout this region increase frictional and inertial losses within the mixture. At low submergence ratios, slug, churn, and annular flows push the water rather than displacing it, allowing the two phases to work together more efficiently. 
Geometrical parameters such as the gas void fraction and phase interfaces play a large role in two-phase fluid flow. Mishima and Ishii describe a strong wake effect from individual bubbles as the main cause to transition the mixture flow from the slug to churn regime ${ }^{59}$.

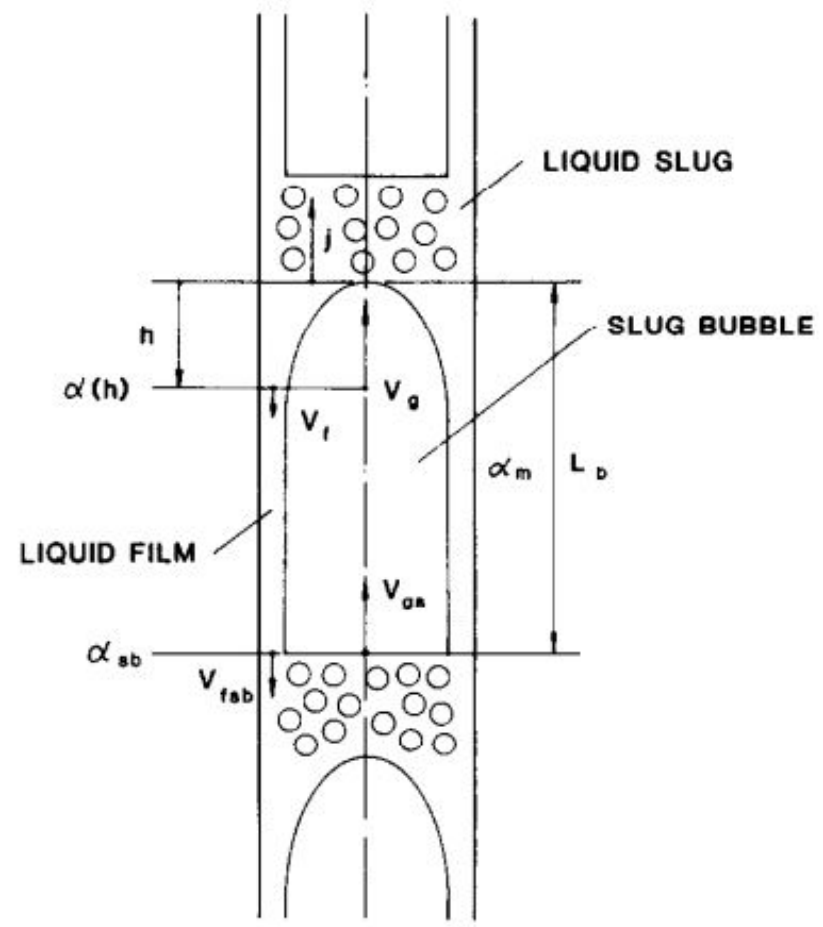

Figure 20: The transition frame from slug flow to churn flow is shown in this diagram ${ }^{59}$.

Figure 20 is a depiction of the slug flow model used for the transition criteria between slug flow and churn flow. The important variables with respect to modeling this transition are the length of the slug bubble, $\mathrm{L}_{\mathrm{b}}$, and the local velocities of the gas and liquid, $\mathrm{V}_{\mathrm{f}}$ and $\mathrm{V}_{\mathrm{g}}$.

Figure 21 shows the variation of water and air mass flow rates in an airlift mechanism with different submergence ratios in a tube with a $50 \mathrm{~mm}$ diameter and $6 \mathrm{~m}$ height ${ }^{53}$. For low air mass flow rates, generally below $20 \mathrm{~kg} / \mathrm{hr}$, the buoyancy forces are too weak to lift the mixture to the free surface, or in this case the separator tank. The authors noticed the coalescence of air bubbles as air flow rate is increased, and a slug flow that formed that pushed the trapped water toward the top. 


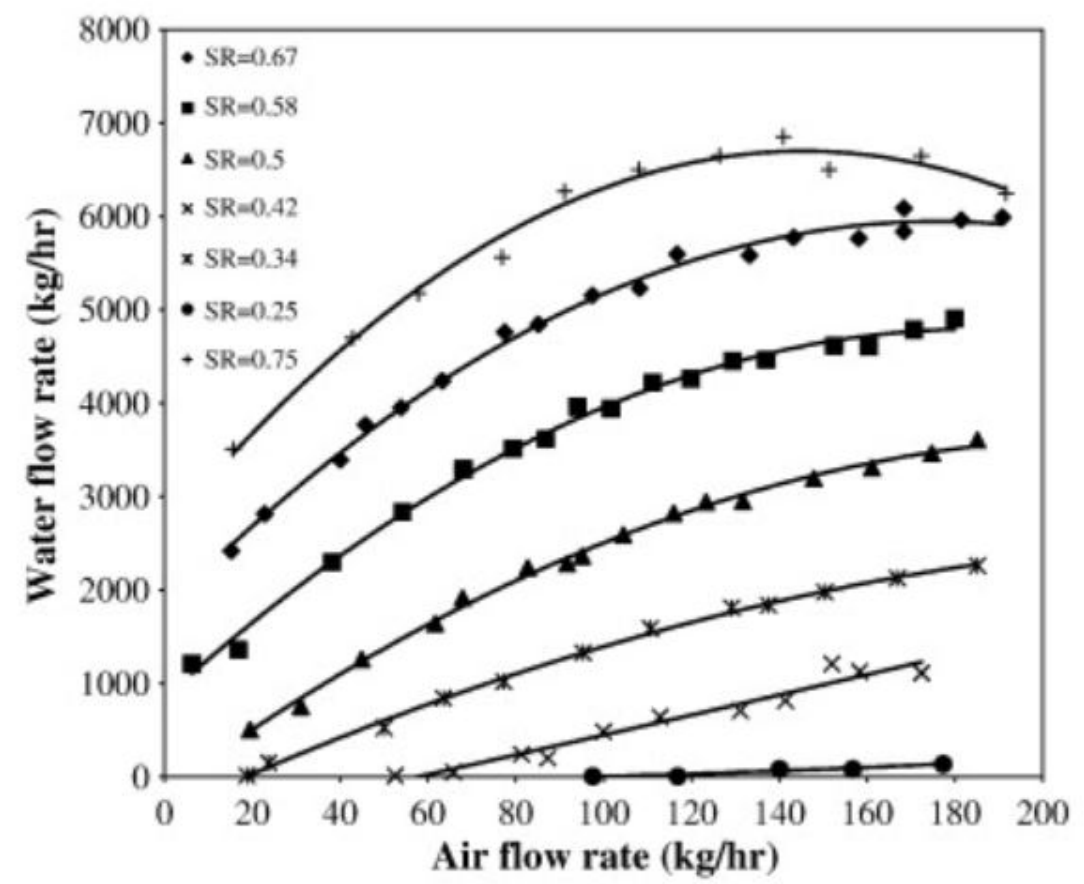

Figure 21: Flow rates for air and water with several submergence ratios is shown ${ }^{53}$.

The critical point of the graphs can be described as the transition from a churn-slug flow to an annular-slug flow. This switch decreases the water flow rate at the outlet, which reduces the efficiency of the pump.

A population balance model (PBM) can be considered for use in the airlift approach to simulate bubble coalescence and break-up. The PBM is linked to the equations for motion of flow and the two-phase regime is better modeled under a combined CFD-PBM approach ${ }^{60}$. A discretized population balance method can lead to a large numerical analysis ${ }^{61}$. Some efforts can be made to reduce this analysis, however, which include solving a transport equation to generate a profile for the interfacial area.

\subsubsection{Macroscale Consideration of Multi-point Air Injection}

Mahrous carried out an experiment to numerically study the effects of multistage air injection on the performance of an airlift pump ${ }^{62}$. The experiment assumed the air was compressible and ideal, mass was not exchanged between phases, and all phases were isothermal. The last assumption would not be true for geothermal applications, but the work can still show the effects 
of multi-stage injection on the airlift efficiency. There is less energy required to inject this air at shallower depths. Greater depths call for more energy to compress the air to the higher pressures experienced further down the well.

Figure 22 shows the results of a single-, two-, three-, and five-stage air injection model with a diameter of $26 \mathrm{~mm}$, tube height of $6.74 \mathrm{~m}$, and submergence ratio of $0.7^{62}$. At each stage, the compressed air was injected at equal flow rates. Both axes are in terms of air and liquid volumetric flux, or flow rate divided by the cross-sectional area $(\mathrm{j}=\mathrm{Q} / \mathrm{A})$.

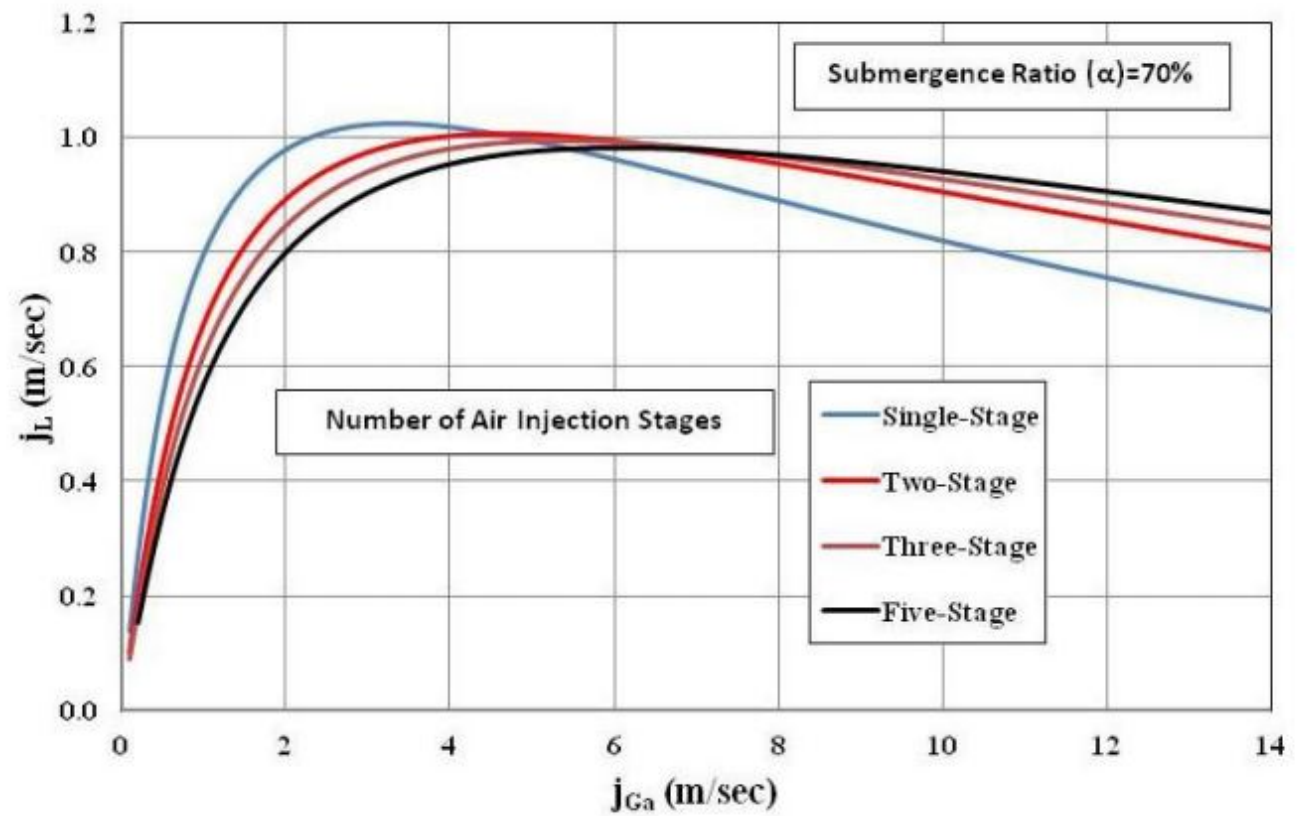

Figure 22: Multi-point air injection is desired for an air flow flux above the critical point ${ }^{62}$.

It is shown that increasing injection points past a certain air volumetric flux, approximately 6 $\mathrm{m} / \mathrm{sec}$, will increase the liquid output at the surface. Up to that air flux, a single stage air injection point will yield more recoverable liquid. Taleb and Al-Jarrah concluded in their study of an airlift pump that for the same air flux, the maximum efficiency of the pump and maximum water flux increase as the submergence ratio increases ${ }^{63}$. 


\section{Conclusion}

The geothermal energy reservoirs across the globe are largely untapped and advancing the methods to capture the energy is the next step for the industry to move forward. Most current geothermal systems use lineshaft or submersible pumps to extract the brine, which use expensive and down-hole parts that require maintenance. The proposed method reviewed in this report is to develop an innovative geothermal technology by using airlift principles and capitalizing on the density differential between two-phase mixtures.

A background search into the current geothermal market and pumping techniques supplemented the literature review of the modeling of two-phase flow. In the microscale, important properties of the injected fluid such as gas flow rate and bubble sizes will drive the technology. From there, CFD can be implemented to compute the variables and analyze the characteristics of the flow regime. A macroscopic approach to modeling the well will involve the understanding and in-depth analysis of the bubble, slug, churn, and annular flow regimes.

The literature reviewed in this report suggests there is still work to be done to fully understand the airlift principles and two-phase flow regimes. The modeling of a geothermal well is difficult due to the corrosive conditions and high pressures experienced. The best technique for the airlift pump approach at the microscale is a lattice-Boltzmann method with focus on the sparger orifice size, and gas flow rate. Euler-Lagrange approaches could also be used after further exploration with the use of modern computational methods. The intermediate scale should involve a comprehensive CFD simulation process that considers the turbulence and gas hold-up that will be experienced. The macroscale will focus on the flow regimes and whether a multi-point injection process will help the brine reach the surface.

The experimental work completed in this field is assumptive and at this point in the research it would be difficult to apply their results to a geothermal pump. Applying these computational and analytical methods to live wells is the next step in the experimental process. While the fluid properties and initial conditions may not be fully calculated or defined, useful simulations and profiles can be generated to advance the work for the airlift principles, and the geothermal industry as a whole. 


\section{References}

1 National Geographic Society. “Geothermal Energy.” National Geographic Society, Nov. 16, 2012.

2 “Energy Flow Charts:” LLNL Flow Charts, Department of Energy, Apr. 2020.

3 Tapia, D. and de Lourdes, C. "Analysis of Cost and Energy Performance of Geothermal Heat Pump Systems in Southern Louisiana." 2017.

4 "Electricity Generation: Geothermal." Energy.gov, U.S. Department of Energy. Accessed July 11, 2020.

5 Moon, H. and Zarrouk, S. "Efficiency of Geothermal Power Plants: A Worldwide Review." Geothermics, Vol. 51: 142-153. 2014.

6 Clark, N., Musho, T., and Mink, R., Proposal to DE-FOA-000185, 2018. (unpublished)

7 "Geothermal Explained." Independent Statistics and Analysis, U.S. Energy Information Administration, Mar. $25,2020$.

8 Lund, John W. "Geothermal District Heating.” U.S. Department of Energy, Conference Presentation, July 2015.

9 "Geothermal Explained - Where Geothermal Energy is Found." Independent Statistics and Analysis, U.S. Energy Information Administration, Dec. 5, 2019.

10 Gunnlaugsson, Einar. "Geothermal District Heating in Reykjavik, Iceland." International Geothermal Days, Stanford University, Sept. 2004.

11 Lund, J. W. and Toth, A. N. "Direct Utilization of Geothermal Energy 2020 Worldwide Review." Proceedings World Geothermal Congress. 2020.

12 Lund, John W. "Direct Utilization of Geothermal Energy.” Energies (19961073) 3 (8): 1443-71. 2010.

13 Spijker, H. and Ungemach, P. "Definition of Electrosubmersible Pump (ESP) Design and Selection Workflow." Blaskracht, Netherlands. 2016.

14 Ravier, G., Graff, J. J., and Villadangos, G. "Operating a Lineshaft Production Pump in a Small Pump Chamber Under Highly Aggressive Geothermal Fluid Conditions: Results from the Soultz EGS Site." Proceedings, World Geothermal Congress, Melbourne. 2015.

15 Takács, Gábor. "Electrical Submersible Pumps Manual : Design, Operations, and Maintenance. 2nd Ed." Gulf Professional Publishing. 2017.

16 Li, K., Han, Y., and Wang, T. "A Novel Prediction Method for Down-Hole Working Conditions of the Beam Pumping Unit Based on 8-directions Chain Codes and Online Sequential Extreme Learning Machine." Journal of Petroleum Science and Engineering, Vol. 160: 285-301. 2018.

17 Miska, S., Sharaki, A., and Rajtar, J. M. "A Simple Model for Computer-Aided Optimization and Design of Sucker-Rod Pumping Systems." Journal of Petroleum Science and Engineering, Vol. 17, No. 3-4: 303-312. 1997.

18 Chemical Engineering. "Gas Sparging. " Essentials for the CPI Professional. Sept. 1, 2012. 
19 Dhotre, M. T. and Joshi, J. B. "Design of a Gas Distributor: Three-dimensional CFD Simulation of a Coupled System Consisting of a Gas Chamber and a Bubble Column." Chemical Engineering Journal, Vol. 125, No. 3: 149-163. 2007.

20 Kulkarni, A. V. and Joshi, J. B. "Design and Selection of Sparger for Bubble Column Reactor. Part I: Performance of Different Spargers." Chemical Engineering Research and Design, Vol. 89, No. 10: 19721985. 2011.

21 SGS Minerals. "Spargers and Sparging Technology.” July 1, 2016.

22 Barelli, A., et al. "Prediction of Geothermal Well Pressure and Temperature Profiles." Geothermics, Vol. 23 No. 4: 339-353. 1994.

23 Watson, Arnold. "Geothermal Drilling and Well Design." Geothermal Engineering: Fundamentals and Applications, Springer-Verlag New York Inc., 2013.

$24 \mathrm{He}, \mathrm{X}$. and Luo, L. "Theory of the Lattice Boltzmann Method: From the Boltzmann Equation to the Lattice Boltzmann Equation." Physical Review E 56, 1997.

25 Philippi, P. C., et al. "High-Order Lattice-Boltzmann.” Journal of the Brazilian Society of Mechanical Sciences and Engineering. 2016.

26 Khalloufi, M., et al. "High Fidelity Anisotropic Adaptive Variational Multiscale Method for Multiphase Flows with Surface Tension." Computer Methods in Applied Mechanics and Engineering, Vol. 307: 44-67. 2016.

27 Kurtoglu, I. O. and Lin, C.L. "Lattice Boltzmann Study of Bubble Dynamics." Numerical Heat Transfer, Part B: Fundamentals, Vol. 50, No. 4: 333-351. 2006.

28 Inamuro, T., et al. "A Lattice Boltzmann Method for Incompressible Two-Phase Flows with Large Density Differences.” Journal of Computational Physics, Vol. 198, No. 2: 628-644. 2004.

29 Sungkorn, R., Derksen, J. J., and Khinast, J. G. "Euler-Lagrange Modeling of a Gas-Liquid Stirred Reactor with Consideration of Bubble Breakage and Coalescence." A. I. Ch. E. Journal, Vol. 58, No. 5: 1356-1370. 2012.

30 Laakkonen, M., et al. "Modelling Local Bubble Size Distribution in Agitated Vessels." Chemical Engineering Science, Vol. 62: 721-740. 2007.

31 Lain, S., et al. "Modelling Hydrodynamics and Turbulence in a Bubble Column Using the Euler-Lagrange Procedure." International Journal of Multiphase Flow, Vol. 28, No. 8: 1381-1407. 2002.

32 Kazakis, N. A., Mouza, A. A., and Paras, S. V. "Experimental Study of Bubble Formation at Metal Porous Spargers: Effect of Liquid Properties and Sparger Characteristics on the Initial Bubble Size Distribution." Aristotle University. Jan. 5, 2007.

33 “Navier-Stokes Equations.” NASA,, May 5, 2015. www.grc.nasa.gov/www/k-12/airplane/nseqs.html.

34 Bhaskaran, R. and Collins, L. "Introduction to CFD basics." Cornell University-Sibley School of Mechanical and Aerospace Engineering: 1-21. 2002.

35 Ghorai, S. and Nigam, K. D. P. "CFD Modeling of Flow Profiles and Interfacial Phenomena in Two-Phase Flow in Pipes.” Chemical Engineering and Processing: Process Intensification, Vol. 45, No. 1: 55-65. 2006. 
36 Mubarok, M., Zarrouk, S., and Cater, J. "Numerical and Analytical Modeling of Pressure Drop Through a Geothermal Two-Phase Orifice Plate.” Proceedings 40th New Zealand Geothermal Workshop, Vol. 14. 2018.

37 Saleh, S. N., et al. "CFD Assesment of Uniform Bubbly Flow in a Bubble Column." Journal of Petroleum Science and Engineering, Vol. 161: 96-107. 2018.

38 Zhiyin, Yang. "Large-eddy Simulation: Past, Present and the Future." Chinese Journal of Aeronautics, Vol. 28, No. 1: 11-24. 2015.

39 Vaidheeswaran, A. and Hibiki, T. "Bubble-induced Turbulence Modeling for Vertical Bubbly Flows." International Journal of Heat and Mass Transfer, Vol. 115: 741-752. 2017.

40 Colombo, M. and Fairweather, M. "Multiphase Turbulence in Bubbly Flows: RANS Simulations." International Journal of Multiphase Flow, Vol. 77: 222-243. 2015.

41 Ma, T., et al. "Scale-adaptive Simulation of a Square Cross-Sectional Bubble Column." Chemical Engineering Science, Vol. 131: 101-108. 2015.

42 Jain, D., Kuipers, J. A. M., and Deen, N. G. "Numerical Study of Coalescence and Breakup in a Bubble Column Using a Hybrid Volume of Fluid and Discrete Bubble Model Approach." Chemical Engineering Science, Vol. 119: 134-146. 2014.

43 Fuster, D. and Popinet, S. "An All-Mach Method for the Simulation of Bubble Dynamics Problems in the Presence of Surface Tension." Journal of Computational Physics, Vol. 374: 752-768. 2018.

44 Moshtari, B., Babakhani, E. G., and Moghaddas, J. S. "Experimental Study of Gas Hold-up and Bubble Behavior in Gas-Liquid Bubble Column." Petroleum and Coal, Vol. 51, No. 1: 27-32. 2009.

45 Parisien, V., et al. "Bubble Swarm Characteristics in a Bubble Column under High Gas Holdup Conditions." Chemical Engineering Science, Vol. 157: 88-98. 2017.

46 Macchi, A. "Dimensionless Hydrodynamic Simulation of High Pressure Multiphase Reactors Subject to Foaming." Department of Chemical and Biological Engineering, University of British Columbia. 2002.

47 Levich, V. G. and Spalding, D.B. "Physicochemical Hydrodynamics." Prentice-Hall, Englewood Cliffs, NJ. 1962.

48 Sriram, K. and Mann, R. "Dynamic Gas Disengagement: A New Technique for Assessing the Behaviour of Bubble Columns." Chemical Engineering Science, Vol. 32, No. 6: 571-580. 1977.

49 Taitel, Y., Bornea, D., and Dukler, A. E. "Modeling Flow Pattern Transitions for Steady Upward Gas-Liquid Flow in Vertical Tubes." A. I. Ch. E. Journal, Vol. 26, No. 3: 345-354. 1980.

50 Malekzadeh, R., Henkes, R., and Mudde, R. F. "Severe Slugging in a Long Pipeline-Riser System: Experiments and Predictions." International Journal of Multiphase Flow Vol. 46: 9-21. 2012.

51 Clark, N. and Flemmer, R., 'Predicting the Holdup in Two-Phase Bubble Upflow and Downflow Using the Zuber and Findlay Drift-Flux Model,’ A. I. Ch. E. Journal, Vol. 31, No. 3: 500-503. 1985.

52 Clark, N. and Dabolt, R., "A General Design Equation for Air Lift Pumps Operating in Slug Flow," A. I. Ch. E. Journal, Vol. 32, No. 1: 56-64. 1986. 
53 Hanafizadeh, P., Ghanbarzadeh, S., and Saidi, M. H. "Visual Technique for Detection of Gas-Liquid TwoPhase Flow Regime in the Airlift Pump." Journal of Petroleum Science and Engineering, Vol. 75, No. 3-4: 327-335. 2011.

54 Montoya, G., et al. "A Review on Mechanisms and Models for the Churn-Turbulent Flow Regime.” Chemical Engineering Science, Vol. 141: 86-103. 2016.

55 Vermeer, D. J. and Krishna, R. "Hydrodynamics and Mass Transfer in Bubble Columns in Operating in the Churn-Turbulent regime." Industrial \& Engineering Chemistry Process Design and Development, Vol. 20, No. 3: 475-482. 1981.

56 Chen, R. C., et al. "Flow Structure in a Three-Dimensional Bubble Column and Three-Phase Fluidized Bed." $A$. I. Ch. E. Journal, Vol. 40, No. 7: 1093-1104. 1994.

57 Beyer, M., et al. "Air-Water Experiments in a Vertical DN200-pipe." FZD-505 Wissenschaftlich-Technische Berichte. 2008.

58 Lucas, D., et al. "A New Database on the Evolution of Air-Water Flows Along a Large Vertical Pipe." International Journal of Thermal Sciences, Vol. 49, No. 4: 664-674. 2010.

59 Mishima, K. and Ishii, M. "Flow Regime Transition Criteria for Upward Two-Phase Flow in Vertical Tubes." International Journal of Heat and Mass Transfer, Vol. 27, No. 5: 723-737. 1984.

60 Bhole, M. R. and Joshi, J. B., and Ramkrishna, D. "CFD Simulation of Bubble Columns Incorporating Population Balance Modeling." Chemical Engineering Science, Vol. 63, No. 8: 2267-2282. 2008.

61 Krepper, E., et al. "The Inhomogeneous MUSIG Model for the Simulation of Polydispersed Flows." Nuclear Engineering and Design, Vol. 238, No. 7: 1690-1702. 2008.

62 Mahrous, A. F. "Performance of Airlift Pumps: Single-Stage vs. Multistage Air Injection." American Journal of Mechanical Engineering, Vol. 2, No. 1: 28-33. 2014.

63 Taleb, F. and Al-Jarrah, J. "Experimental Study of an Air Lift Pump." Engineering, Technology, \& Applied Science Research, Vol. 7, No. 3: 1676-1680. 2017. 